\title{
Finite element analysis of timber-glass walls
}

\author{
Boštjan Ber • Miroslav Premrov • \\ Andrej Štrukelj
}

Received: 29 December 2015 / Accepted: 15 March 2016 / Published online: 1 April 2016

(C) Springer International Publishing Switzerland 2016

\begin{abstract}
The paper presents a finite element analysis (FEA) of experimentally investigated timber-glass composite walls. So far a series of mechanical tests with in-plane monotonous static and quasi-static cyclic loading were carried out on timber-glass walls with the goal to analyse their general behaviour and to experience failure mechanisms that occur. Timber-glass walls consisted of glass panes, adhesively bonded to the timber frame with different types of adhesives, i.e. silicone, polyurethane and epoxy. FEA was limited to timberglass walls subjected only to monotonous static loading. A commercial finite element code Ansys was used to perform the simulation of experiments. As the types of adhesive are decisive for the behaviour of timberglass walls, additional experiments on bulk adhesives are briefly discussed. The main aim of the performed FEA was to build as accurate as possible mathematical model of timber-glass walls to achieve the correct general behaviour, failure mechanisms and to confirm the composite action in case of using flexible adhesives, e.g. silicone and polyurethane. Geometrically nonlinear finite element method was used including solid
\end{abstract}

\section{B. Ber $(\varangle)$}

Kager hiša d.o.o., Ptuj, Slovenia

e-mail: bostjan.ber@gmail.com

B. Ber · M. Premrov · A. Štrukelj

Faculty of Civil Engineering, Transportation Engineering and Architecture, University of Maribor, Ptuj, Slovenia hexahedral finite elements. Some variations of material models and mesh size were performed to calibrate the numerical model with the results of experimental investigations in order to reach the desired response. The above described experimental and FE investigations present a starting point for a comprehensive parametric study.

Keywords FEA · Nonlinear FE method · Timberglass composites $\cdot$ Adhesives $\cdot$ In-plane load

\section{Introduction}

Timber-frame wall elements (i.e. panel walls) represent a basic structural element of the prefabricated timber structure. Panel walls consist of sheathing boards, mechanically fastened to a timber frame by means of staples, nails or self-tapping screws. They have the ability to transmit both vertical (e.g. snow and dead load) and horizontal loads, caused by gusts of wind or an earthquake.

In a contemporary lightweight timber-frame building a series of fixed glazing is present due to lighting conditions and for solar heat gains during the heating season, which contribute significantly to the energy efficiency of the building, (Žegarac Leskovar et al. 2013). However, a glazed part of building's envelope is unusable in terms of structural integrity. Since the contribution of stiffness and load-bearing capacity of glass surfaces has been neglected so far, additional problems, 
e.g. structural irregularity and uneven distribution of horizontal force can occur.

For this matter, a possibility to integrate insulating glass units (IGU) into the timber structure with thoughtful details has been investigated.

It should be noted that the current state of the art in the field of timber structures is very conservative in relation to the use of glass in structural purposes, mainly due to the lack of investigations and guidelines for the design of glass and timber-glass composite structures. A starting point for the development of the European standard for the design of glass structures represents the report of the European Commission entitled "Guidance for European Structural Design of Glass Components,, (Feldmann et al. 2014), in which all previous investigations on glass elements and structures are collected. However, it states (pp. 66 and 152) that there are no rules or even guidelines for using shear wall panels as primary load-bearing elements. Only requirements for the secondary elements, wherein wall panels loaded perpendicular to its plane are listed in (Feldmann et al. 2014).

A special motivation to find missing answers on the latter subject encouraged us to carry out an extensive investigation on timber-glass composite wall elements. The main goal was to achieve higher overall stiffness of the building and more even distribution of a horizontal force on panel walls. The assumed loadbearing capacity and stiffness of timber-glass wall elements were established by the use of different assembly concepts, whereby the variation of the adhesive, bond line conditions and outer dimensions of timberglass walls were made. Among the adhesives, suitable for joining timber and glass, we limited our choice to silicone, polyurethane and epoxy. An extensive smallscale laboratory tests were carried out on those as well.

\section{Methods}

Timber-glass walls were investigated experimentally and numerically as well. In following sections the experimental part of investigation is briefly introduced to indicate the manner of mechanical testing and to give a technical description of the specimens. Special attention is intended to materials and their constitutive models, which is crucial for further presented numerical study.

\subsection{Experimental study}

Experimental investigations on timber-glass walls were divided into two parts. First part includes mechanical racking tests of timber-glass walls while a second part involves shake-table tests of one- and two-story timber-glass building setups. The latter can be found in Ber et al. (2015) and is not further discussed in this work.

To carry out the mechanical tests, two groups of timber-glass walls were formed, namely TG and TGWE. Figure 1 presents specimens of the first testing group TG, which have common outer dimensions and boundary conditions. TG-DS concept consists of two $6.0 \mathrm{~mm}$ thick glass plates, which are adhesively bonded onto a timber frame with a two-component silicone. TG-S, TG-P and TG-E concepts, where a single $10 \mathrm{~mm}$ thick thermally toughened glass pane is placed in the mid-plane of the timber frame, differ from each other depending on the type of adhesive, namely two-component silicone, one-component polyurethane and two-component epoxy. Similar selection of adhesives and joint types was used by Niedermaier (2005) for timber-glass and Huveners (2009) for steel-glass connections. To determine the strength and stiffness characteristics of TG walls, they were fixed to the testing rig and subjected to a standardized racking test according to (EN 594 1996, 2011). An increasing monotonic load $\left(F_{h}\right)$ represents e.g. wind or seismic load.

Figure 1 shows the composition and appearance of TG type walls as well as a detailed description of elements and their dimensions. A more extensive description of the experimental study on TG walls is available in Ber et al. (2014).

Prefabricated wall elements with fixed insulating glass units have been in use for quite a while, however never before for structural reason. In particular they can be found in timber-frame construction (Kolb 2008). In general, two different types of timber-glass wall elements (TGWE) appear in such structures. In the first type, an IGU is of approximately square dimensions, while the second type has two narrow IGUs separated by an additional timber stud. In this way, TGWE specimens were designed, as seen in Fig. 2.

In this concept, a groove between a three-layer IGU and a timber frame is filled with a one-component polyurethane adhesive over the entire circumference. A minor step was thus added to the technological process 


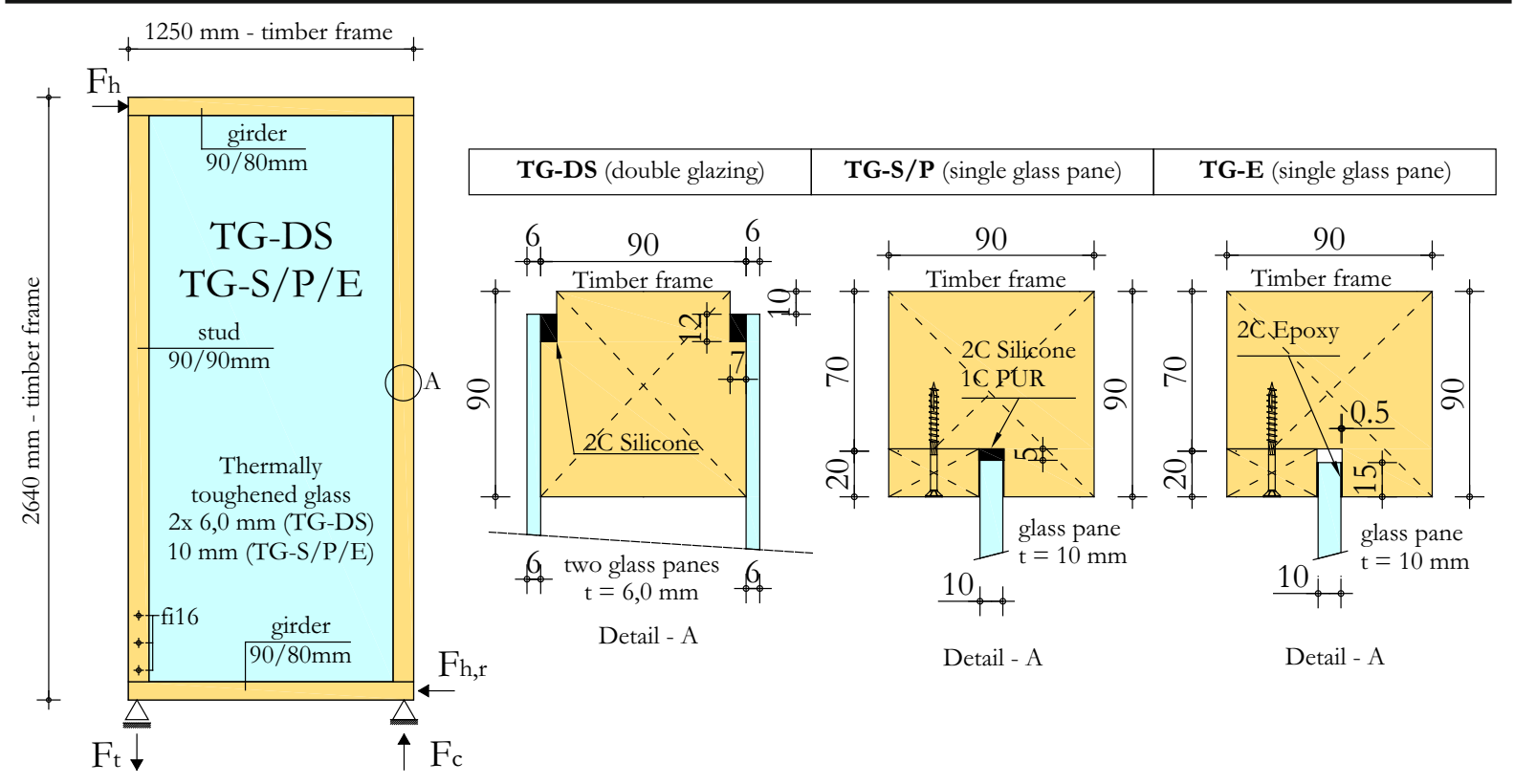

Fig. 1 Static system and assembly details of TG walls
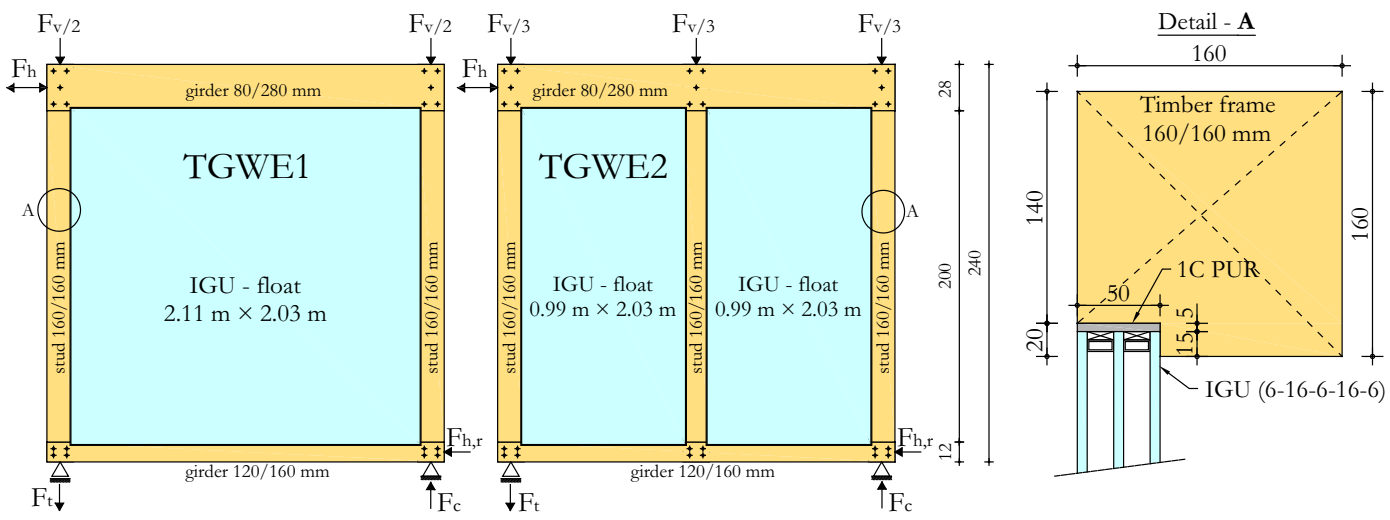

Fig. 2 Static system and assembly details of TGWE walls

of prefabrication to obtain a load-bearing composite shear wall. TGWE walls were subjected to racking tests according to (EN 5942011 ) and quasi-static cyclic tests according to (ISO 166702003 ) in order to analyse the wall's ductility, strength and stiffness degradation. TGWE walls were subjected to a combination of vertical load, $F_{v}$, (e.g. load of a roof and floor structure) and horizontal load, $F_{h}$, (e.g. wind or seismic load).

Dimensions of TGWE walls with a structural assembly detail is shown in Fig. 2. While the boundary conditions are schematically presented, a detailed description can be found in Ber et al. (2015).

\subsection{Material models}

Wood is an organic substance and thus exposed to external factors during growth, which is reflected in its non-homogeneity and anisotropy. The latter feature of growing differs between three mutually perpendicular directions, i.e. longitudinal, radial and tangential (Green et al. 1999). Therefore a linear-elastic orthotropic material model was used to describe the wood properly, whereby we ignored the difference between tangential and radial directions. Consequently six independent elastic constants are sufficient to describe elastic properties of wood, which are listed in 
Table 1 Elastic constants and mechanical properties of wood

\begin{tabular}{|c|c|c|c|c|c|c|c|c|c|c|c|c|c|c|}
\hline Material & Behaviour & $\begin{array}{l}\mathrm{E}_{0(\mathrm{X})} \\
(\mathrm{MPa})\end{array}$ & $\begin{array}{l}\mathrm{E}_{90(\mathrm{Y})} \\
(\mathrm{MPa})\end{array}$ & $\begin{array}{l}\mathrm{E}_{90(\mathrm{Z})} \\
(\mathrm{MPa})\end{array}$ & $\begin{array}{l}v_{X Y} \\
(-)\end{array}$ & $\begin{array}{l}v_{Y Z} \\
(-)\end{array}$ & $\begin{array}{l}v_{X Z} \\
(-)\end{array}$ & $\begin{array}{l}\mathrm{G}_{\mathrm{XY}} \\
(\mathrm{MPa})\end{array}$ & $\begin{array}{l}\mathrm{G}_{\mathrm{YZ}} \\
(\mathrm{MPa})\end{array}$ & $\begin{array}{l}\mathrm{G}_{\mathrm{XZ}} \\
(\mathrm{MPa})\end{array}$ & $\begin{array}{l}\mathrm{f}_{\mathrm{m}, \mathrm{k}} \\
(\mathrm{MPa})\end{array}$ & $\begin{array}{l}\mathrm{f}_{\mathrm{t}, 0, \mathrm{k}}^{\mathrm{a}} \\
(\mathrm{MPa})\end{array}$ & $\begin{array}{l}\mathrm{f}_{\mathrm{c}, 0, \mathrm{k}}^{\mathrm{a}} \\
(\mathrm{MPa})\end{array}$ & $\begin{array}{l}\rho_{\mathrm{m}} \\
\left(\mathrm{kg} / \mathrm{m}^{3}\right)\end{array}$ \\
\hline Spruce C24 & Lir & 11,000 & 660 & 660 & 0.42 & 0.245 & 0.42 & 690 & 33 & 69 & 2 & 12 & 21 & 420 \\
\hline Spruce GL24h & Linear & 11,600 & 700 & 700 & & & & 720 & 35 & 720 & 24 & 16.5 & 24 & 456 \\
\hline
\end{tabular}

a Values for longitudinal direction parallel to the grain

Table 2 Mechanical properties of glass, steel, concrete and aluminum

\begin{tabular}{|c|c|c|c|c|c|c|c|}
\hline Material & Behaviour & $\mathrm{E}(\mathrm{MPa})$ & $v$ & $\mathrm{G}(\mathrm{MPa})$ & $\mathrm{f}_{\mathrm{t}}(\mathrm{MPa})$ & $\mathrm{f}_{\mathrm{c}}(\mathrm{MPa})$ & $\rho\left(\mathrm{kg} / \mathrm{m}^{3}\right)$ \\
\hline Thermally toughened glass & Linear & 70,000 & 0.2 & 29,167 & 120 & 500 & 2500 \\
\hline Float glass & Linear & & & & 45 & & \\
\hline Steel & Linear & 200,000 & 0.3 & 76,923 & 250 & 250 & 7850 \\
\hline Concrete & Linear & 31,000 & 0.2 & 12,917 & - & - & 2500 \\
\hline Material & Behaviour & $\mathrm{E}(\mathrm{MPa})$ & $v$ & $\mathrm{G}(\mathrm{MPa})$ & $\mathrm{f}_{\mathrm{y}}(\mathrm{MPa})$ & $\mathrm{E}_{\mathrm{t}}(\mathrm{MPa})$ & $\rho\left(\mathrm{kg} / \mathrm{m}^{3}\right)$ \\
\hline Aluminum & Bilinear & 71,000 & 0.33 & 26,692 & 280 & 500 & 2770 \\
\hline
\end{tabular}

Table 1. Mechanical properties for sawn (C24) and laminated timber (GL24h) were obtained from standards (EN 338 2003; EN 1194 2000), respectively. Absent values of Poisson's coefficients $\left(v_{\mathrm{ij}}\right)$ and shear moduli $\left(\mathrm{G}_{\mathrm{ij}}\right)$ were taken from Green et al. (1999).

The behaviour of glass under increasing load is linearly elastic up to an instantaneous brittle failure. In case of TG type walls, thermally toughened glass was used (EN 12150-1 2000), while insulating glass units (IGU) in case of TGWE type walls were composed of three float glass panes (EN 572-1 2004). Mechanical properties of glass are listed in Table 2.

For other materials, that appear in the mathematical models (steel, concrete and aluminum), the default material properties from the extensive material library of the commercial finite element code Ansys were used (Table 2). All mechanical connectors (i.e. screws, threaded rods, pins), support stirrups, angle brackets and hold-downs were made of steel. Reinforced concrete was used as the foundation for TGWE walls. For steel and concrete we assumed a linear elastic behaviour, therefore an isotropic elastic material model was used. For aluminum spacers between glass panes of the IGU, a bilinear elasto-plastic model with isotropic hardening was chosen.

Additional mechanical tests were performed to determine the structural performance of adhesives for timber-glass walls when subjected to short-term sta- tic loads. The adhesives tested were a two-part silicone Ködiglaze $\mathrm{S}$; a polyurethane Ködiglaze $\mathrm{P}$ and a two part epoxy Körapox 558 all produced by Kömmerling. The aim of uniaxial tensile tests was to determine the visco-elastic and elasto-plastic properties independently of each other (Overend et al. 2011). Two types of specimen's geometry were used, namely S3a (DIN 53504 2010) and 1B (EN 527-2 2012). Uniaxial tensile tests, performed on Zwick Z030 testing machine were divided into two interconnected parts. First the visco-elastic properties were obtained followed by a discrete loading strategy which was applied to establish the elasto-plastic properties. It was necessary to undertake these investigations on the adhesives in order to establish some of the fundamental mechanical properties, which were not available from the manufacturer. However, some of the mechanical properties required to characterize the stiffness of the bulk material were available in the adhesive's data sheets provided by the manufacturer. Those are listed in the first portion of Table 3.

To study the visco-elastic response of the chosen adhesives, a series of uniaxial tension stress-relaxation tests were performed. Specimens were first subjected to instantaneous uniform tension (at a strain rate of $50 \mathrm{~mm} / \mathrm{min}$ ) until a predefined extension was reached. The extension was then held constant and the stress relaxation as a function of time was recorded. A decay 
Table 3 Mechanical properties given by the manufacturer (first part of the table) and evaluated visco-elastic properties of the adhesives (second part of the table)

\begin{tabular}{|c|c|c|c|c|c|c|c|c|c|c|c|c|c|}
\hline Material & Behaviour & $\begin{array}{l}\mathrm{E} \\
(\mathrm{MPa})\end{array}$ & $\begin{array}{l}\mathrm{G} \\
(\mathrm{MPa})\end{array}$ & $\begin{array}{l}v \\
(-)\end{array}$ & $\begin{array}{l}\mathrm{f}_{\mathrm{t}} \\
(\mathrm{MPa})\end{array}$ & $\begin{array}{l}\mathrm{f}_{\mathrm{v}} \\
(\mathrm{MPa})\end{array}$ & $\begin{array}{l}\varepsilon_{\max } \\
(\%)\end{array}$ & $\begin{array}{l}\rho \\
\left(\mathrm{kg} / \mathrm{m}^{3}\right)\end{array}$ & $\begin{array}{l}\mathrm{T}_{\mathrm{MIN}} \\
\left({ }^{\circ} \mathrm{C}\right)\end{array}$ & $\begin{array}{l}\mathrm{T}_{\mathrm{MAX}} \\
\left({ }^{\circ} \mathrm{C}\right)\end{array}$ & $\begin{array}{l}\mathrm{G}_{\nu} \\
(\mathrm{MPa})\end{array}$ & $\begin{array}{l}\mathrm{t}_{\mathrm{d}} \\
(\mathrm{s})\end{array}$ & $\begin{array}{l}\beta \\
(1 / s)\end{array}$ \\
\hline Silicone & Nonlinear & 2.8 & 0.93 & 0.5 & 2.1 & 2.1 & 230 & 1370 & -40 & +150 & 0.351 & 100 & 0.0026 \\
\hline Polyurethane & Nonlinear & 1 & 1.3 & 0.49 & 2 & 2 & 450 & 1170 & -30 & +70 & 0.454 & 290 & 0.0016 \\
\hline Epoxy & Nonlinear & 2800 & $960^{*}$ & $0.4^{*}-0.46^{*}$ & $28^{*}$ & $20-22$ & l & 1500 & -30 & +120 & 135.4 & 3600 & 0.0022 \\
\hline
\end{tabular}

* Values estimated by the manufacturer

Table 4 Evaluated elasto-plastic properties of the adhesives

\begin{tabular}{|c|c|c|c|c|}
\hline Adhesive & $\begin{array}{l}\text { Time independent elasto-plastic } \\
\text { stress-strain polynomial }\end{array}$ & $\mathrm{R}^{2}$-value & $\begin{array}{l}\text { Mean failure } \\
\text { stress } \\
\sigma_{\text {mean }}(\mathrm{MPa})\end{array}$ & $\begin{array}{l}\text { Mean failure } \\
\text { strain } \\
\varepsilon_{\text {mean }}\end{array}$ \\
\hline \multicolumn{5}{|c|}{ Specimen's geometry $\mathrm{S} 3 \mathrm{a}\left(\mathrm{L}_{0}=50 \mathrm{~mm} ; \mathrm{L}_{\text {gauge }}=10 \mathrm{~mm}\right)$} \\
\hline Silicone & $\sigma=1.6856 \varepsilon^{3}-1.2884 \varepsilon^{2}+1.9703 \varepsilon+0.0098$ & 0.9995 & 5.065 & 1.411 \\
\hline Polyurethane & $\sigma=2.6085 \varepsilon^{4}-3.5412 \varepsilon^{3}-0.0408 \varepsilon^{2}+3.7315 \varepsilon+0.01$ & 0.9985 & 4.012 & 1.229 \\
\hline Epoxy & $\begin{aligned} \sigma & =2 \mathrm{E}+07 \varepsilon^{3}-197510 \varepsilon^{2}+624.69 \varepsilon+0.5383 \text { for } 0.00021 \\
& \leq \varepsilon \leq 0.00485\end{aligned}$ & 0.9999 & 1.397 & 0.0035 \\
\hline \multicolumn{5}{|c|}{ Specimen's geometry $1 \mathrm{~B}\left(\mathrm{~L}_{0}=150 \mathrm{~mm} ; \mathrm{L}_{\text {gauge }}=50 \mathrm{~mm}\right)$} \\
\hline Silicone & $\sigma=2.5384 \varepsilon^{3}-1.3669 \varepsilon^{2}+1.8454 \varepsilon-0.014$ & 0.9834 & 2.542 & 0.937 \\
\hline Polyurethane & $\sigma=2.1977 \varepsilon^{4}-3.3422 \varepsilon^{3}+0.8279 \varepsilon^{2}+2.1857 \varepsilon-0.0003$ & 0.9779 & 2.650 & 1.204 \\
\hline Epoxy & $\sigma=692508 \varepsilon^{3}-22633 \varepsilon^{2}+478 \varepsilon+0.0302$ & 0.9739 & 4.130 & 0.014 \\
\hline
\end{tabular}

time $t_{d}$, was reached when the stress fell to the constant value. Further the stress vs. time curve was converted into shear modulus vs. time curve, from which the visco-elastic shear modulus $G_{\nu}$ was obtained. Viscoelastic properties for each adhesive are summarised in Table 3. For this test we used only specimens with S3a geometry, prepared by the manufacturer.

To establish the elasto-plastic properties of the chosen adhesives, specimens were loaded in 5-10 increments up to failure. In each increment the load was kept constant for a period $t_{d}$, which we defined in the preceding visco-elastic tests. An expression for the timeindependent elasto-plastic stress-strain relationship for each type of the adhesive was obtained by polynomial curve fitting of the discrete stabilised points. Elastoplastic properties were evaluated for all three chosen adhesives and separately for each specimen's geometry. The results are summarised in Table 4 .

Finite element code Ansys contains an extensive library of material models, which can simulate different behaviour of the same material. By using available material characteristics of the adhesives, we chose two different hyperelastic models and elasto-plastic material model with isotropic hardening. Table 5 shows the selected material models of adhesives with constants (hyperelastic models) and descriptions. Designation of the FE model is composed of adhesive specimen's geometry followed by a manner of load application in uniaxial tensile test wherein " $\mathrm{M}$ " denotes a monotonically increasing load and "EP" denotes cyclic loading protocol.

Hyperelasticity is the property of rubber-like materials that exhibit elastic response at high strains. Such a behaviour is also observed when testing and working with the silicone. To determine the hyperelastic response of the silicone we used Arruda-Boyce strain energy function, which is useful for the level of strains up to the value of $300 \%$ (Ansys 2014).

The used polyurethane adhesive, which material properties are similar to those of silicone (Table 3), also shows hyperelastic behaviour. However, polyurethane exhibits twice the elongation of the silicone, therefore Ogden strain energy function was used. Compared to other, Ogden strain energy function provides the best 
Table 5 Selected material models for each type of adhesive

\begin{tabular}{|c|c|c|c|c|}
\hline Adhesive & FE model designation & \multicolumn{3}{|c|}{ Material model (Ansys designation) } \\
\hline & & Hyperelastic-Arruda-B & yce (TB HYPER BOYCE) & \\
\hline \multirow[t]{5}{*}{ Silicone } & $\mathrm{S} 3 \mathrm{a}(\mathrm{M})$ & $\begin{array}{l}\text { Initial shear modulus } \mu \\
(\mathrm{MPa})\end{array}$ & $\begin{array}{l}\text { Limiting network stretch } \lambda_{L} \\
(-)\end{array}$ & $\begin{array}{l}\text { Incompressibility parameter } \mathrm{d}_{1} \\
(1 / \mathrm{MPa})\end{array}$ \\
\hline & & 0.7066 & $2.90 \mathrm{E}+11$ & 0.2143 \\
\hline & $\mathrm{S} 3 \mathrm{a}(\mathrm{EP})$ & \multirow{2}{*}{\multicolumn{3}{|c|}{ Elasto-plastic model with isotropic hardening (TB MISO) }} \\
\hline & $1 \mathrm{~B}(\mathrm{EP})$ & & & \\
\hline & & \multicolumn{3}{|c|}{ Hyperelastic-Ogden (TB HYPER OGDEN) } \\
\hline \multirow[t]{4}{*}{ Polyurethane } & $\mathrm{S} 3 \mathrm{a}(\mathrm{M})$ & $\begin{array}{l}\text { Material constant } \mu_{1} \\
(\mathrm{MPa})\end{array}$ & $\begin{array}{l}\text { Material constant } \alpha_{1} \\
(-)\end{array}$ & $\begin{array}{l}\text { Incompressibility parameter } \mathrm{d}_{1} \\
(1 / \mathrm{MPa})\end{array}$ \\
\hline & & 0.9126 & 14,486 & 0.3 \\
\hline & $\mathrm{S} 3 \mathrm{a}(\mathrm{EP})$ & \multirow{2}{*}{\multicolumn{3}{|c|}{ Elasto-plastic model with isotropic hardening (TB MISO) }} \\
\hline & $1 \mathrm{~B}(\mathrm{EP})$ & & & \\
\hline \multirow[t]{2}{*}{ Epoxy } & $\mathrm{S} 3 \mathrm{a}(\mathrm{M})$ & \multicolumn{3}{|c|}{ Uniaxial tensile test data (TB EXPE UNIAXIAL) } \\
\hline & $\mathrm{S} 3 \mathrm{a}(\mathrm{EP})$ & \multicolumn{3}{|c|}{ Elasto-plastic model with isotropic hardening (TB MISO) } \\
\hline
\end{tabular}

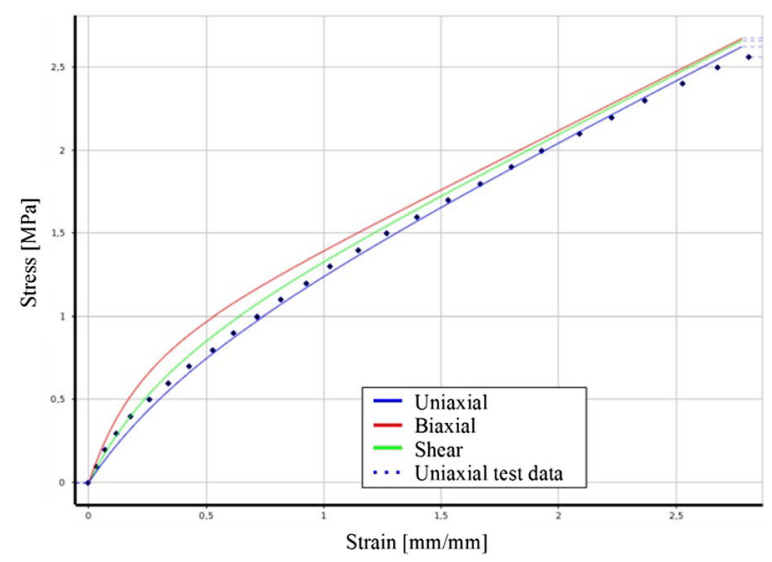

(a)

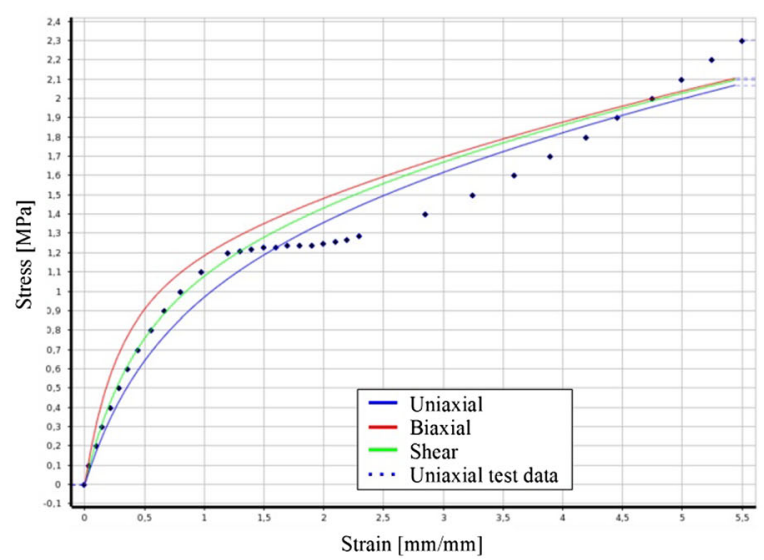

(b)

Fig. 3 The display of calculated hyperelastic relations for a Arruda-Boyce and $\mathbf{b}$ Ogden strain energy function

response at higher levels of strains (up to $700 \%$ ). Based on the entered nominal values of $\sigma-\varepsilon$ uniaxial tensile test, the material constants were calculated (Table 5) and the remaining hyperelastic relations (i.e. biaxial and shear) were estimated as shown in Fig. 3.

The large strain plasticity formulation, which was used to describe the elasto-plastic response of adhesives, takes into account the von Mises criterion of plastification, combined with the assumption of isotropic hardening. Material behaviour was described by entering the data (Table 4) in the form of "true stresslogarithmic strain". The finite element code Ansys pre- sumes that the slope of the curve is equal to zero after the last pair of data is entered.

By entering visco-elastic constants $\left(G_{\nu}\right.$ and $\left.\beta\right)$ the viscous properties of the material are taken into account implicitly through the evaluation of the strain-energy constants, while combining with elasto-plastic material models is not possible.

2.3 Constructing numerical models and simulation of mechanical tests

The idea of the finite element method (FEM) is a division of a complex model into smaller, manageable 


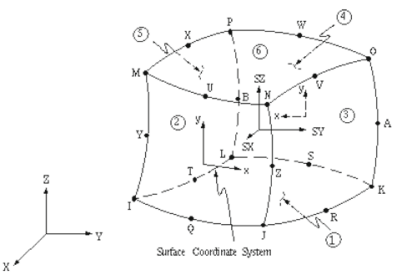

(a)
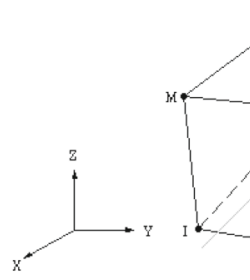

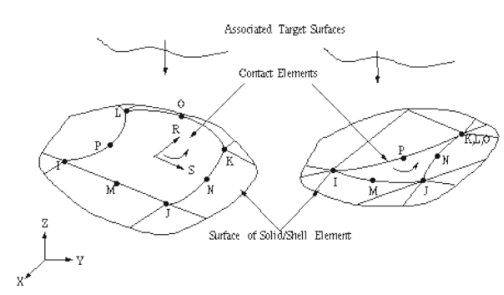

(c)

Fig. 4 Used finite elements: a SOLID95, b HYPER86 and c CONTA174 (Ansys 2014)
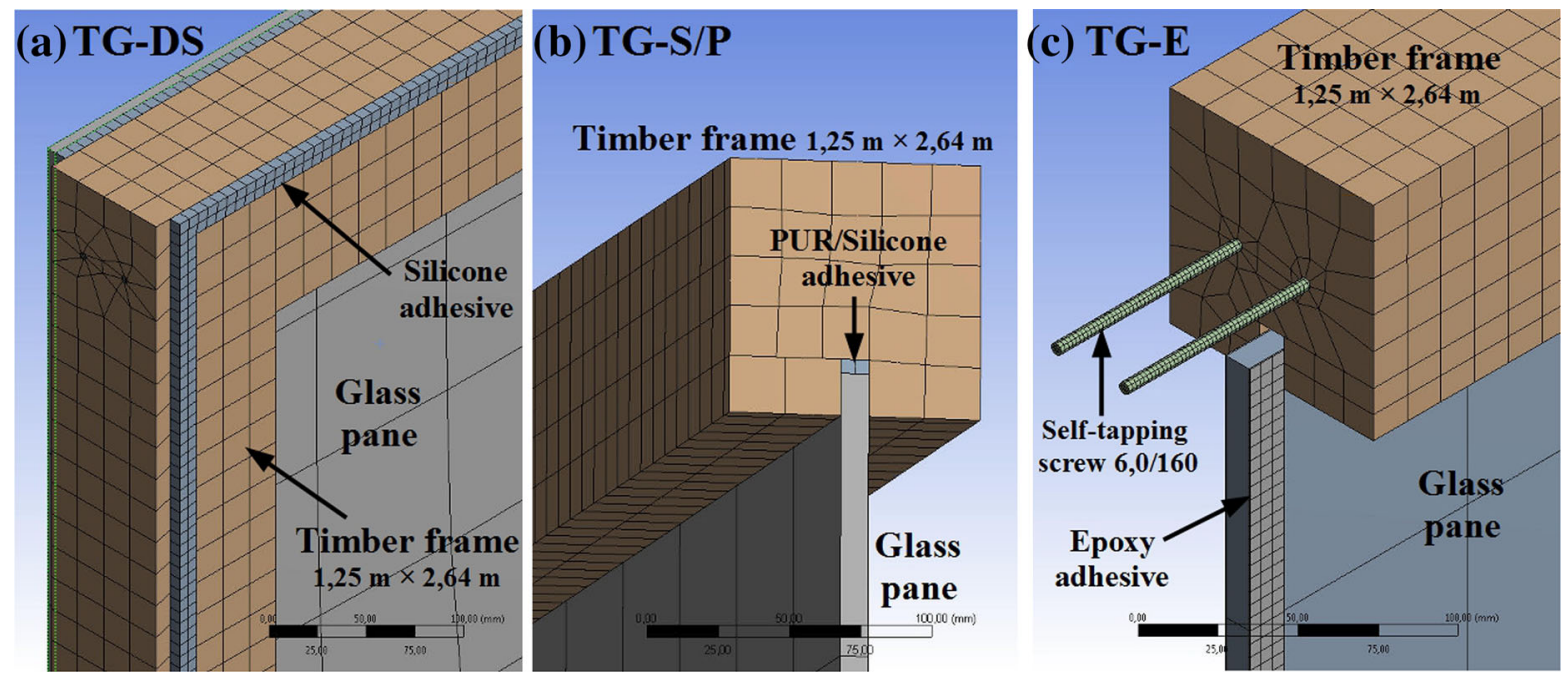

Fig. 5 Mesh details of TG wall's elements

pieces. One of the first finite element analyses of adhesively bonded joint was performed by Adams and Peppiatt back in 1974 (Silva and Campilho 2012).

The purpose of the analysis was to develop accurate numerical models of various experimentally investigated timber-glass wall elements. The main focus was laid on the global behaviour and their response under the influence of external forces. An academic version of the commercial finite element code Ansys R14.5 was used to build and calculate finite element models of TG walls, which were calibrated to measured values of displacements from mechanical tests.

The finite element mesh of timber-glass walls consisted of solid volume elements (SOLID95), defined with 20 nodes and three degrees of freedom per node. Solid element has the ability to achieve large strains and it tolerates irregular shape. For calculating hyperelastic materials (i.e. adhesives), the preferred choice was 8-node solid finite element (HYPER86) designed for high strains and based on a hybrid formulation with constant pressure. This type of element can be used to model compressible and incompressible materials. In each step of the calculation an update of the model geometry is done, due to the ability of achieving large deformations. Touching surfaces between the structural elements were defined using surface-to-surface nonlinear contact elements (CONTA174) with three degrees of freedom per node. Contact elements adopt geometric characteristics of connected solid elements' surfaces. Above mentioned finite elements are shown on Fig. 4.

Finite element mesh for all six test groups of TG and TGWE wall elements is shown on Figs. 5 and 6. For structural elements with the regular shape (i.e. timber frame, glass and adhesive joint) the use of hexahedral solid elements was required. The other elements of irregular shape (e.g. screws, angle brackets, hold-downs, steel rods, etc.) were meshed with tetrahedrons. 

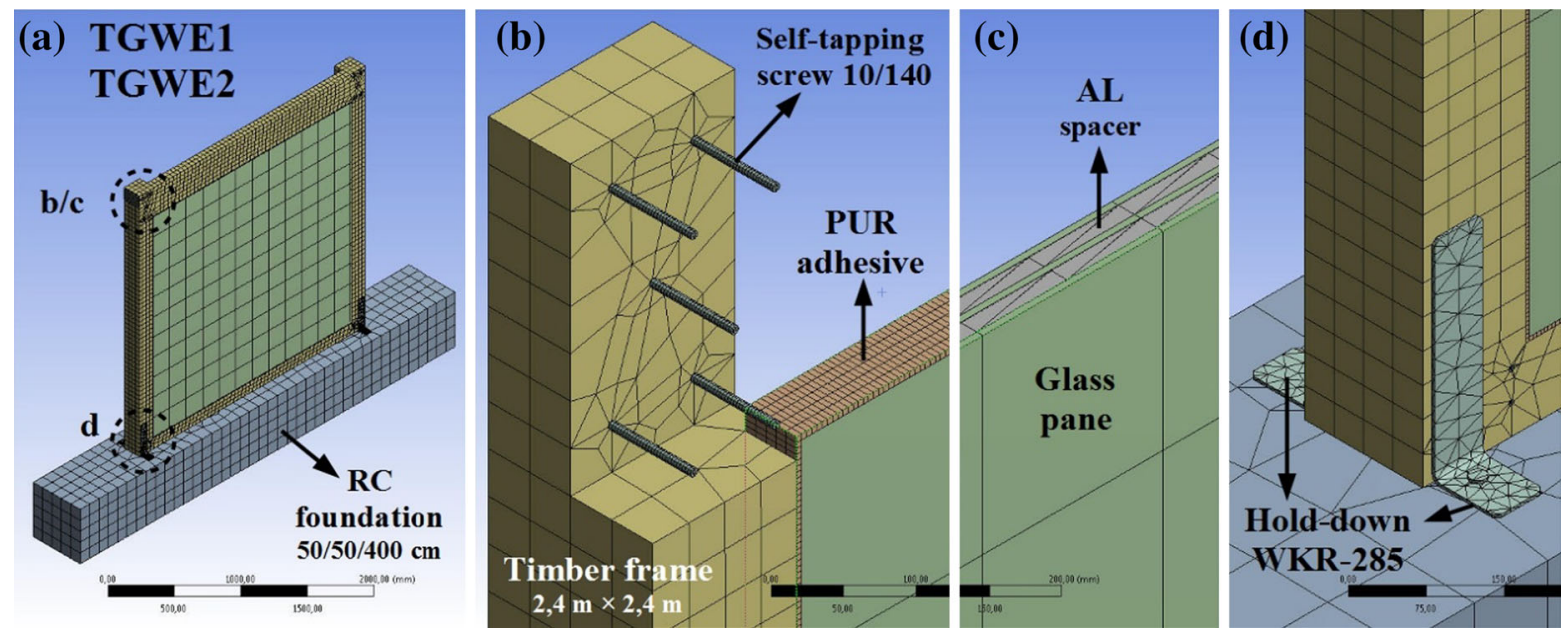

Fig. 6 Mesh details of TGWE wall's elements
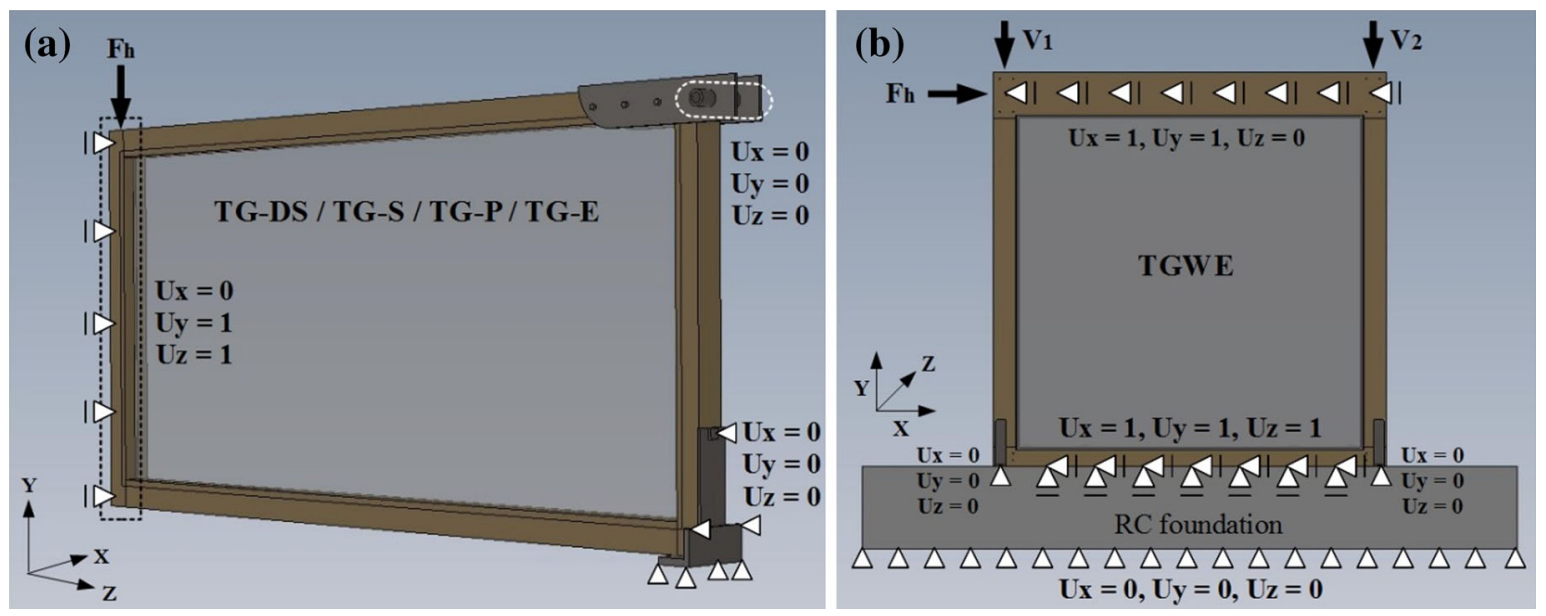

Fig. 7 Boundary conditions of TG and TGWE walls with details of the mounting support (D1 and D2)

Due to relatively different dimensions of the structural elements (see Figs. 5, 6) a manual selective mesh sizing was performed to adjust the mesh quality separate for each member of the timber-glass model.

3D-models of timber-glass walls were positioned and supported in the same manner as in a laboratory. Figure 7 shows the disposition of the simulation, supports and direction of the input load.

Tensile loaded support of the TG type walls (Fig. 7a) is composed of two $8.0 \mathrm{~mm}$ thick steel plates, fastened to a timber frame with three M16 bolts. Steel plates are then hinged to a steel tube with a diameter of $55 \mathrm{~mm}$, which is unmovable. Compressive support was modeled by combining various flat steel elements to achieve the appropriate external dimensions and thickness of the bedding. Steel elements representing the compressive support were restrained as shown in Fig. 7a. Protection against the lateral torsional buckling was simulated with a roller support, allowing only in-plane displacements at the free end of the TG model where the vertical load $F_{h}$, was applied.

In case of TGWE models, a simplified steel angles (type WKR-285) and $12 \times 300 \mathrm{~mm}$ threaded rods were used to simulate the connection with the RC foundation slab, which was fixed along the entire bottom surface (Fig. 7b). However, all translational displacements were released between TGWE model and RC foundation slab to simulate the actual boundary condition in this area. The model was secured against 
tilting with the introduction of a sliding support, which allowed only vertical and horizontal in-plane displacement of the model (Fig. 7b). Connections between the individual components of an assembly were defined by linear (i.e. bonded) and nonlinear (i.e. frictionless, rough and no separation) types of contact elements.

TGWE models were loaded in vertical and horizontal directions. The horizontal load $F_{h}$, was applied to the upper edge of the wall element, as shown in Fig. $7 \mathrm{~b}$. The load increment was simulated with steps of 10 $\mathrm{kN} / \mathrm{s}$, until the value of $70 \mathrm{kN}$ (TGWE2) or $80 \mathrm{kN}$ (TGWE1) was reached. The total vertical load of 60 $\mathrm{kN}$ was applied to the model in the first second of simulation. Vertical load was applied to the model in form of a point load to every column (Fig. 7b).

\section{Results and discussion}

The following section presents the results of numerical analysis where we focus on parameters, which we observed at the experimental investigations. These parameters are:

- Failure mechanisms,

- In-plane displacement ( $w$ and $v$ ) as a function of in-plane load $F_{h}$,

- Stress-strain state in the glass pane.

\subsection{Failure mechanisms of TG and TGWE models}

The deformed shape of the numerical model is the first indicator of appropriate boundary conditions depending on the loading conditions (Silva and Campilho 2012). When analyzing a numerical model TG-DS, an increased deformation of the adhesive joint was observed at approximately $16 \mathrm{kN}$ of vertical load. The value of principal stress in the silicone adhesive joint at this loading stage was approximately $2.7 \mathrm{MPa}$, which is already above its plastic limit (Tables 3,4). The same occurred with mechanically tested specimens ST$\mathrm{O} 1 / \mathrm{O} 2 / \mathrm{O} 3$, where in the range of $16-17 \mathrm{kN}$ the deformations of the adhesive joint started to grow large. Figure 8 shows the deformations of the timber frame and adhesive joint of the numerical model compared with actual deformations, observed in the mechanical tests.

In the test models TG-S and TG-P we observe increased deformation (i.e. opening) of the timber frame's corner from 8.0 to $13 \mathrm{kN}$ of vertical load, which is presented in Fig. 9a. The default value of the friction coefficient, which was applied to the contact between screw and timber has proved to be suitable. Values of numerical results were ranging from 4.0 to $5.0 \mathrm{~mm}$, which are close to values of displacements obtained from the mechanical tests. Those values of displacements were not measured explicitly, however, close to yielding point they amounted approximately 5.0-7.0 $\mathrm{mm}$.

Figure $9 \mathrm{~b}$ shows the failure mechanism of a timber frame corner on TG-E model, where deformations of the vertical timber element perpendicular to the grain are visible, due to the compression of the horizontal timber element. Deformation of the numerical model at $40 \mathrm{kN}$ of vertical load were $2.0 \mathrm{~mm}$, while the deformation of mechanically tested walls at the same vertical load ranged from 3.0 to $4.0 \mathrm{~mm}$. The reason for this difference can be attributed to inhomogeneities of wood, which cannot be modelled exactly. The latter could be simulated with a more detailed discussion of orthotropy, i.e. to differ between the radial and tangential direction. However, in our case this was not possible because timber-glass walls had randomly oriented timber elements.

Characteristic failure mechanisms of TGWE models are shown on Fig. 10. At $70 \mathrm{kN}$ of horizontal load, a shift of $2.7 \mathrm{~mm}$ between the stud and the girder was observed (Fig. 10a, b, d). Measurement of the optical system GOM during the mechanical investigations on the specimen TGWE2-3, at the same value of horizontal load, showed the displacement of $2.4 \mathrm{~mm}$. The difference of $0.3 \mathrm{~mm}$, between the numerical and measured value, confirms a proper response of the timber frame corner joint. The numerical model was also showing displacements and deformations in lower tensile loaded corner (Fig. 10d, e), where a horizontal shift of the joint and uplifting of the timber frame corner off the foundation can be seen. Although uplifting of the timber frame's lower corner is restricted (or rather limited) with a pair of steel hold-downs and two threaded rods (Fig. 10e), a total vertical displacement of the FE model equals to $7.0 \mathrm{~mm}$. However, this is a fairly good result according to measured values ranging from 8.0 to $9.0 \mathrm{~mm}$.

In Fig. 10(c, f), the locations of maximum stresses according to von Mises criterion of plastification are shown. Areas of maximum stresses in the adhesive joint coincide with the initiation of the failure mechanisms, 

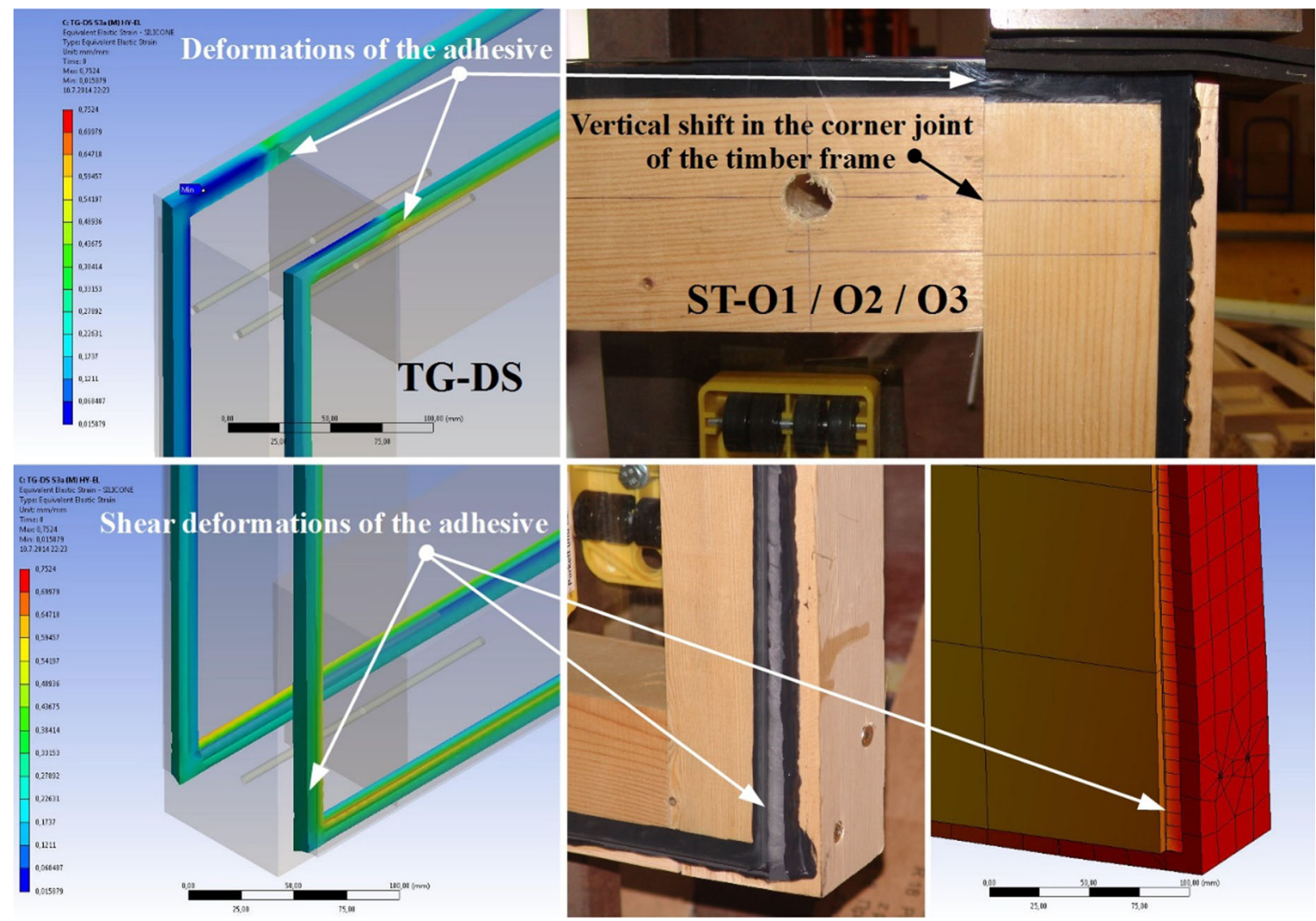

Fig. 8 Failure mechanism of TG-DS test group

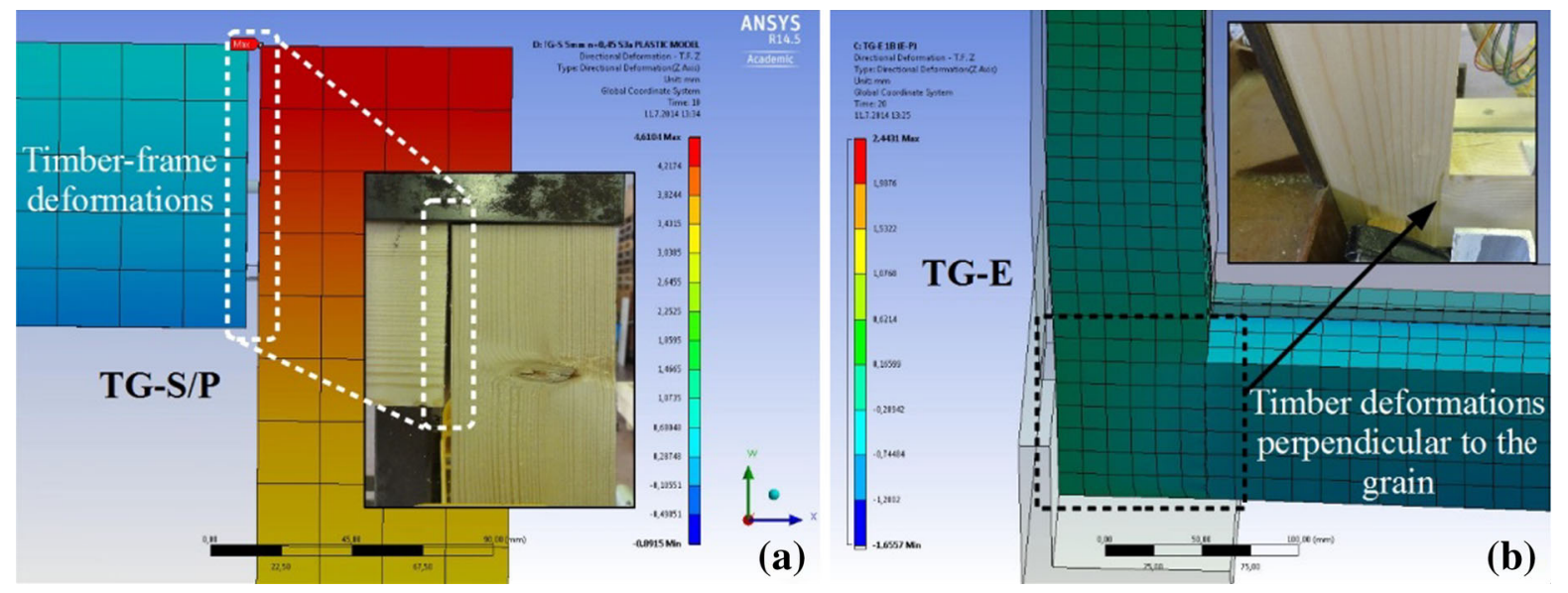

Fig. 9 Matching failure mechanisms of numerical models and experimentally investigated TG-S/P/E walls

shown in Fig. 10(a, b, d). A detailed analysis of this mechanism is not specifically considered, whereas the aim of the investigation is to discuss the general response of the TG systems.
3.2 In-plane displacement of TG and TGWE models

Diagrams of vertical displacement $w$, as a function of vertical load $F_{h}$, for numerical models as well as for 

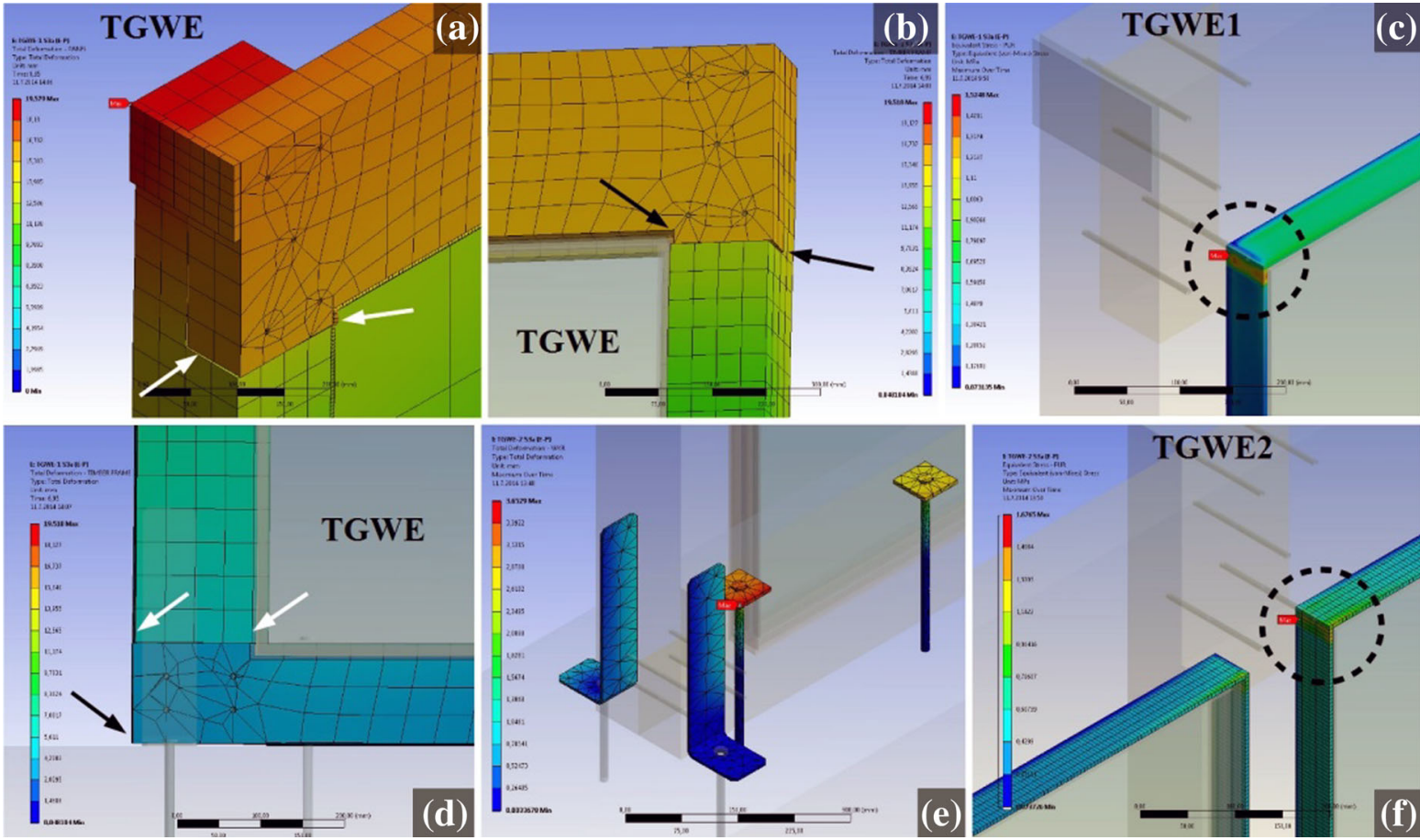

Fig. 10 Failure mechanisms $(\mathbf{a}, \mathbf{b}, \mathbf{d}, \mathbf{e})$ and the state of stress in the adhesive joint $(\mathbf{c}, \mathbf{f})$ in TGWE1 and TGWE2 models

mechanically tested TG walls are presented in Fig. 11. On the left side of Fig. 11(a, c, e), curves of different numerical models are shown, together with the curve of measured mean values. Diagrams on the right side (Fig. 11b, d, f) show the curve of the selected numerical model (best fit) together with measured master curves of the individual experimentally investigated specimen.

For test group TG-DS, only the numerical results using a hyperelastic material model of the silicone adhesive are shown (Fig. 11a, b), due to numerical difficulties of elasto-plastic material models. Even though load-displacement curve of the numerical model does not have the exact shape as the curve of mechanically tested walls, it still possess an approximately equal initial stiffness. Moreover, in the range from 12 to $16 \mathrm{kN}$ the numerical model exhibits comparable vertical displacements with all specimens (ST-O1/O2/O3) as seen from Fig. 11a, b.

In test groups TG-S and TG-P, different material models of adhesives were used (see Table 5). However, the solution converged in all cases. Figure 11(c,e) shows diagrams of different versions of these models, where a slightly higher stiffness of hyperelastic models S3a (M) can be seen. In both groups (TG-S and TG-P), a mesh density variation $(2.5$ and $5.0 \mathrm{~mm})$ with hyperelastic material models of adhesives was made. With this alternation $15 \%$ (TG-S) to $20 \%$ (TG-S) lower value of vertical displacement and more than $10 \%$ higher stiffness was achieved with the models, where a finer mesh of finite elements were used. Although, in both cases (TG-S and TG-P) the most comparable solutions were obtained with a variation of the numerical model, in which an elasto-plastic material models of the adhesive S3a (EP) and 1B (EP) were used. The curve 1B (EP) of the TG-S model (Fig. 11c, d) almost perfectly fits the master curves of ST-S1 and ST-S2, up to the value of $8.0 \mathrm{kN}$. A plastic hinge is then formed at $25 \mathrm{~mm}$ of vertical displacement, indicating the failure of the model. The results of the numerical model TG-P S3a (EP) and 1B (EP) have converged up to 8.0 $\mathrm{kN}$ of vertical load, when they became unstable. The curve TG-P 1B (EP), shown in Fig. 11(e, f), fits best up to $4.0 \mathrm{kN}$ of vertical load and even coincides with the master curve of ST-P3 wall. Numerical $F_{h}-w$ curves of models TG-DS, TG-S and TG-P show an increasing rigidity. There is no noticeable plastification comparing to mechanical tests, where a plastic limit can be clearly observed. Models even exhibit bi-linear 
(a)

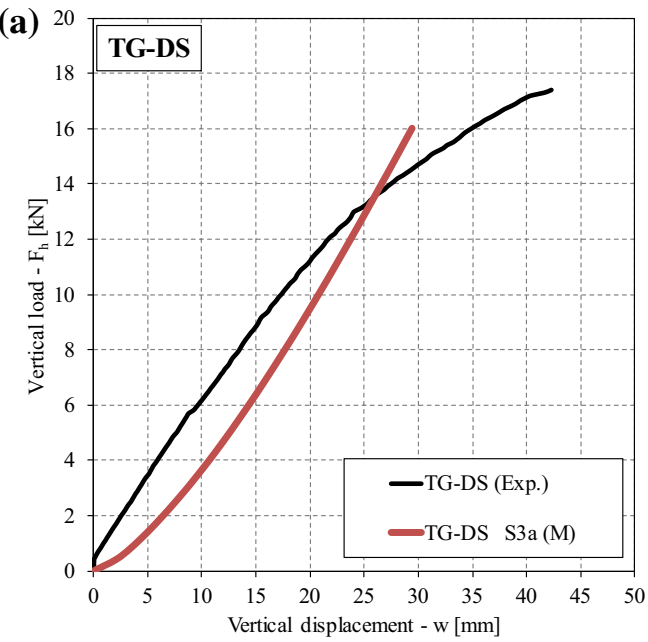

(c)

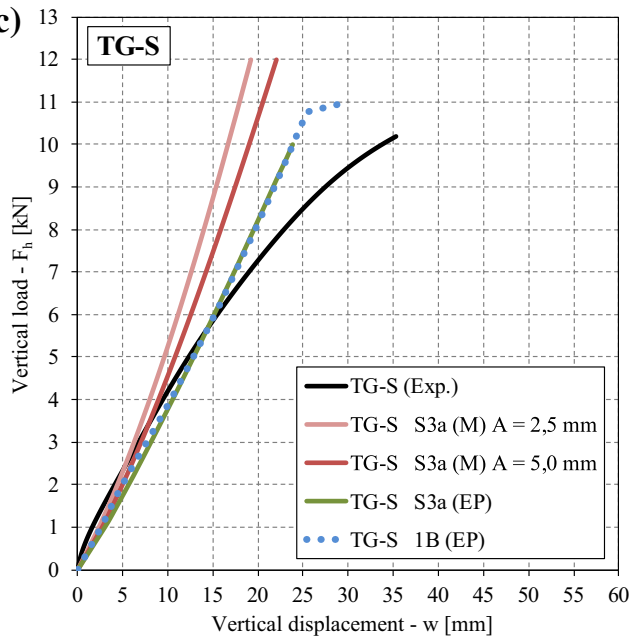

(e)

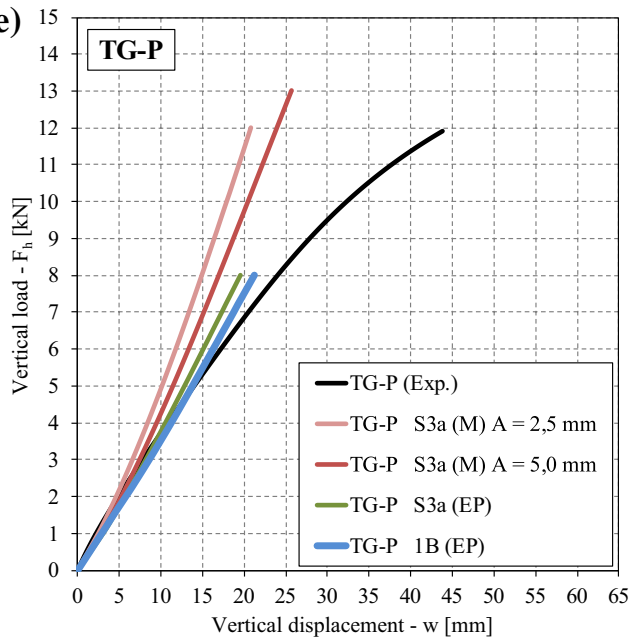

(b)

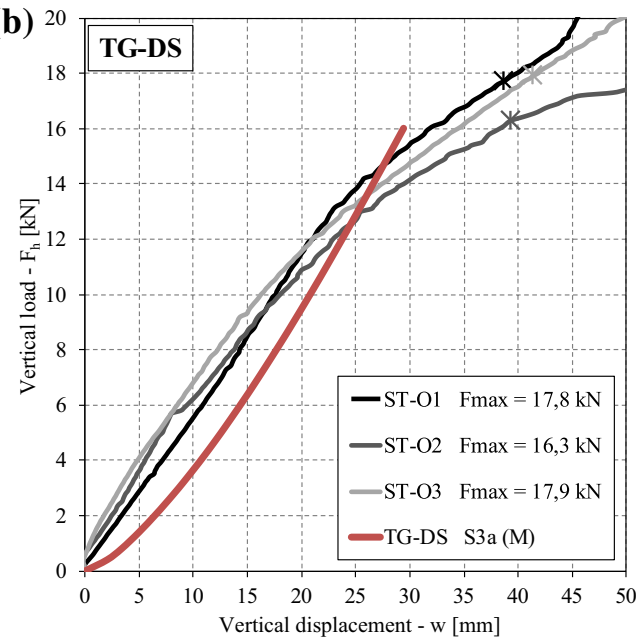

(d)

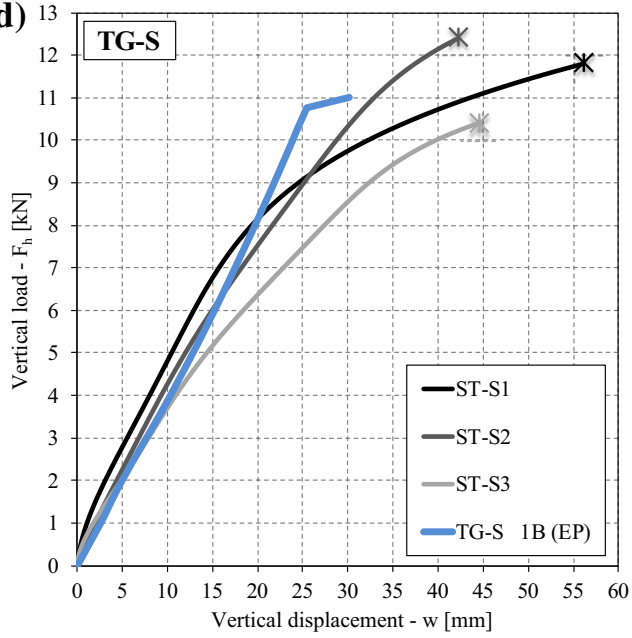

(f)

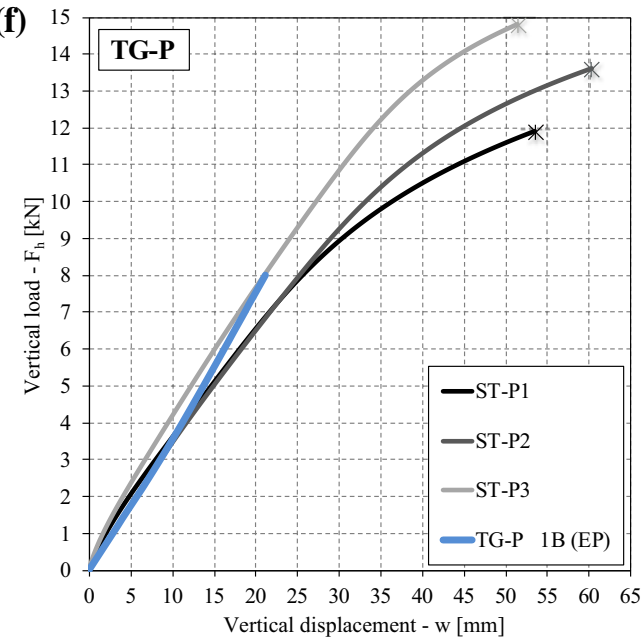

Fig. 11 Diagrams of vertical displacement $(w)$ as a function of vertical load $\left(F_{h}\right)$ for numerical models and experimentally investigated TG-DS (a, b), TG-S (c, d) and TG-P (e, f) types of walls 


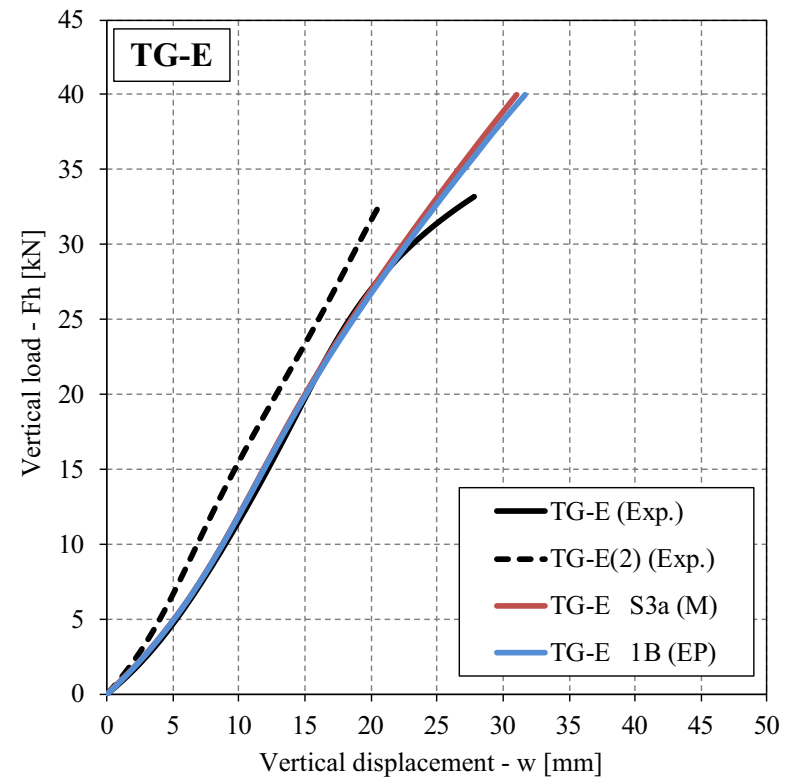

(a)

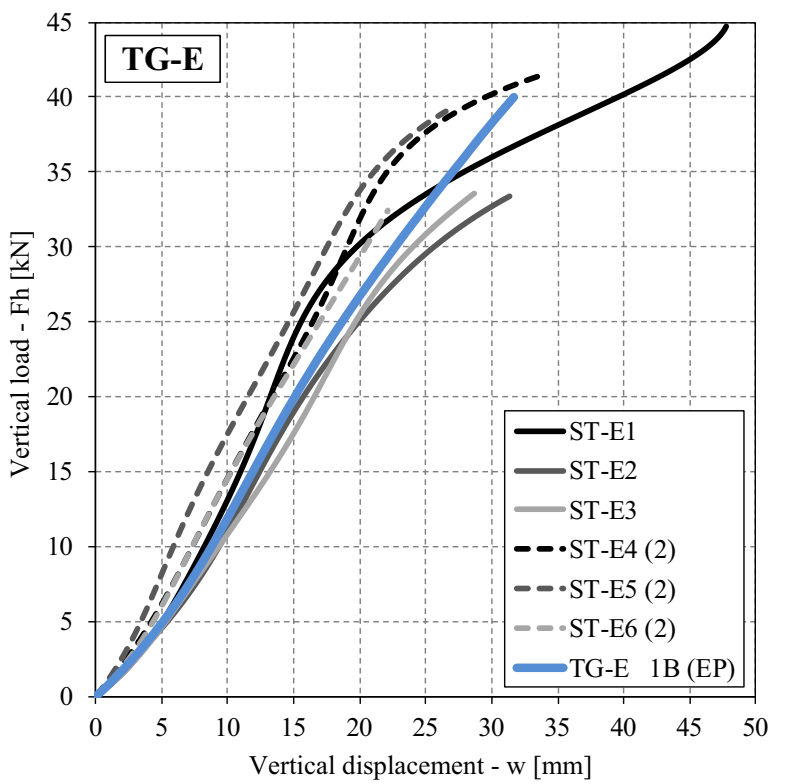

(b)

Fig. 12 Diagrams of vertical displacement $(w)$ as a function of vertical load $\left(F_{h}\right)$ for numerical models and experimentally investigated TG-E type walls

hardening with increasing tangential stiffness. The solution can be found in more complex constitutive models of wood focusing on elastoplasticity and viscoelasticity, proposed by Borst (2012).

When performing non-linear analyzes of TG type walls with flexible adhesive joints (i.e. silicone and polyurethane), we often deal with the problem of convergence. In numerical analysis for each load step a calculation is done. If for the given step or increment of load the calculation does not lead to a solution, a procedure is repeated using smaller intermediate steps. Numerical model does not converge to a solution in case where at reduced load increment the calculation is not possible (Silva and Campilho 2012).

A calculation of two numerical models of TG-E was conducted, namely TG-E S3a (M) and 1B (EP), (see Table 5). Slightly better results were obtained with the elasto-plastic material model of epoxy, 1B (EP), as seen in Fig. 12a. The $F_{h}-w$ diagram in Fig. 12a shows a perfect matching of both numerical models with the experiment up to $30 \mathrm{kN}$ of the vertical load. In the same diagram, the curve of the test group TG-E (2) shows a little higher stiffness. A cause for this is probably the fact that TG-E (2) test group was subjected to an older version of the
(EN 594 1996) testing protocol, which prescribes three cycles of loading, which could influence on the stiffness rate.

From 25 to $40 \mathrm{kN}$, the F-w curve of the model TG-E 1B (EP) does not show signs of plastification or any stiffness degradation. To simulate this effect, it would be sensible to use more advance anisotropic material model of wood. To use this kind of advanced model, extensive mechanical tests should be performed, which is unfortunately beyond the scope of this investigation. However, for an exact prediction of TG walls behaviour this step is necessary in the future.

For each type of timber-glass wall element (TGWE1 and TGWE2) we conducted two numerical models depending on the material model of polyurethane adhesive where S3a (M) represents a hyperelastic and the S3a (EP) elasto-plastic material model.

Figure 13 represents the diagrams of horizontal displacement $v$, at the top of the wall, depending on the horizontal load $F_{h}$, for numerical and physical models of TGWE. Once again, a slightly higher stiffness of the numerical models S3a (M) is observed. Similar occurred with the model TG-P S3a (M) where the difference between the responses when using different 


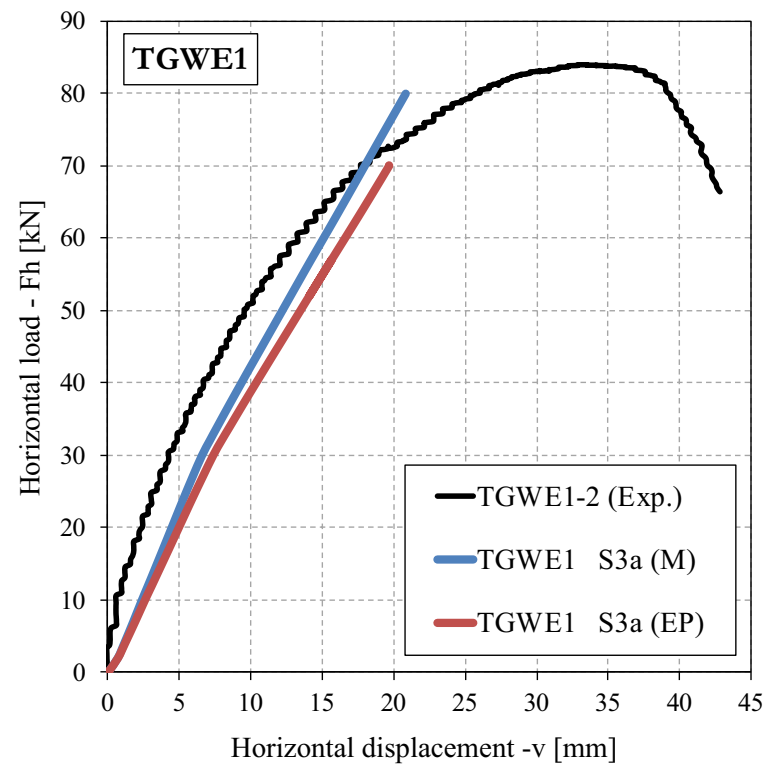

(a)

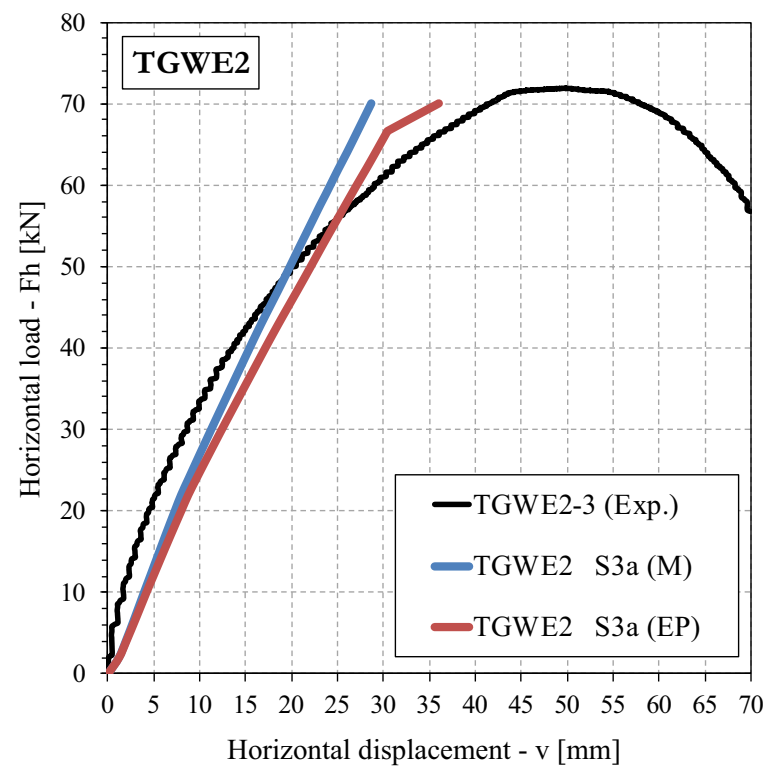

(c)

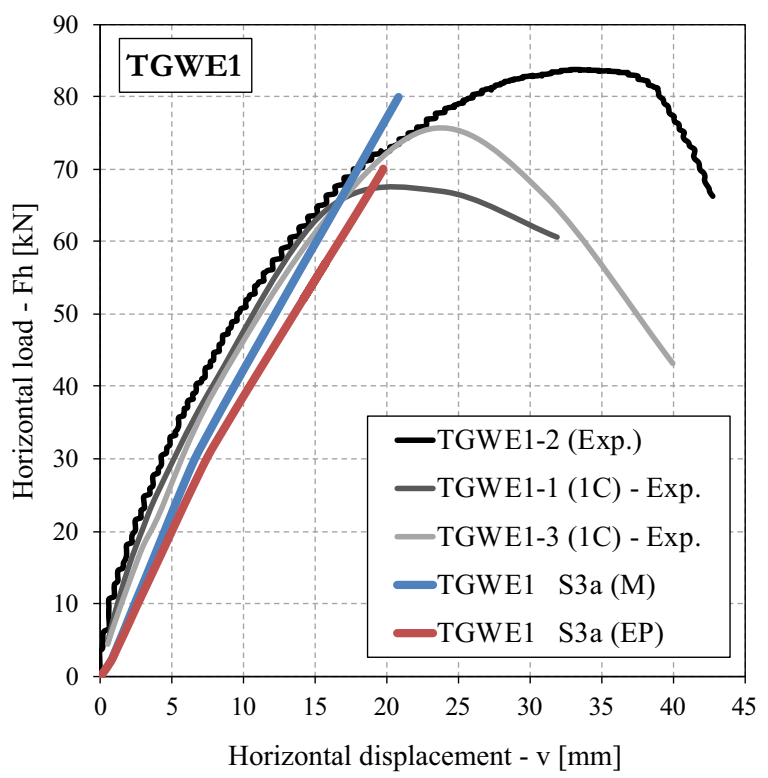

(b)

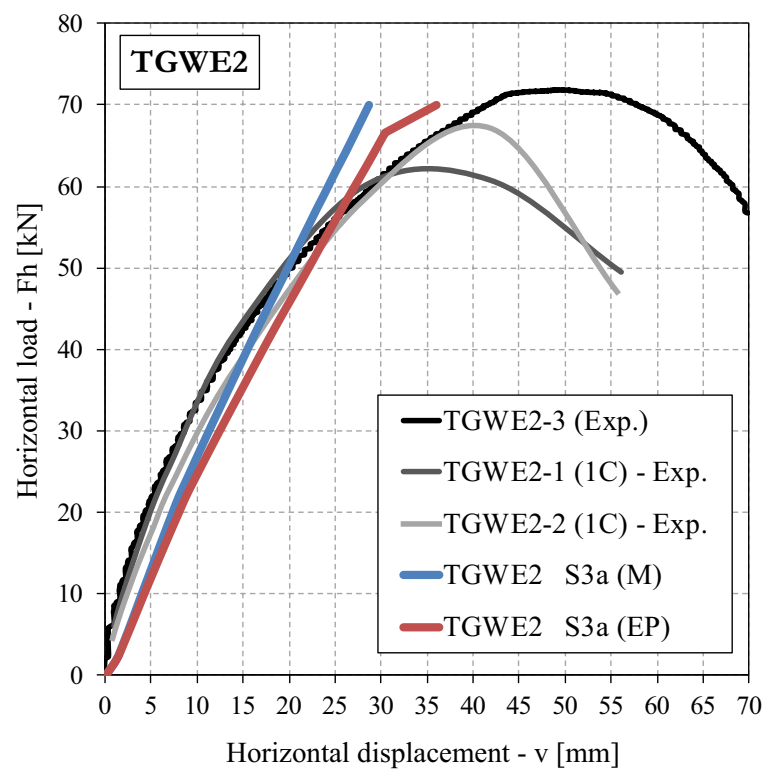

(d)

Fig. 13 Diagrams of horizontal displacement $(v)$ as a function of horizontal load $\left(F_{h}\right)$ for numerical models and experimentally investigated TGWE type walls

material models is much higher, comparing to TGWE models. Results of both TGWE S3a (M) models show more realistic initial stiffness in the range between $0 \mathrm{kN}<F_{h}<50 \mathrm{kN}$ for TGWE1 and $0 \mathrm{kN}<F_{h}<$ $25 \mathrm{kN}$ for TGWE2. From these values of $F_{h}$ on, S3a (EP) models more accurately describe the response of
TGWE1-2 and TGW2-3. After formation of a plastic hinge at approximately $66 \mathrm{kN}$ of $F_{h}$, the TGWE2 S3a (EP) curve is still in a rather good agreement with the slope of the TGWE2-3 (Exp.) curve. Figure 13b and d show the $F_{h}-w$ diagrams, where envelopes of the first cycle of mechanically tested walls subjected 

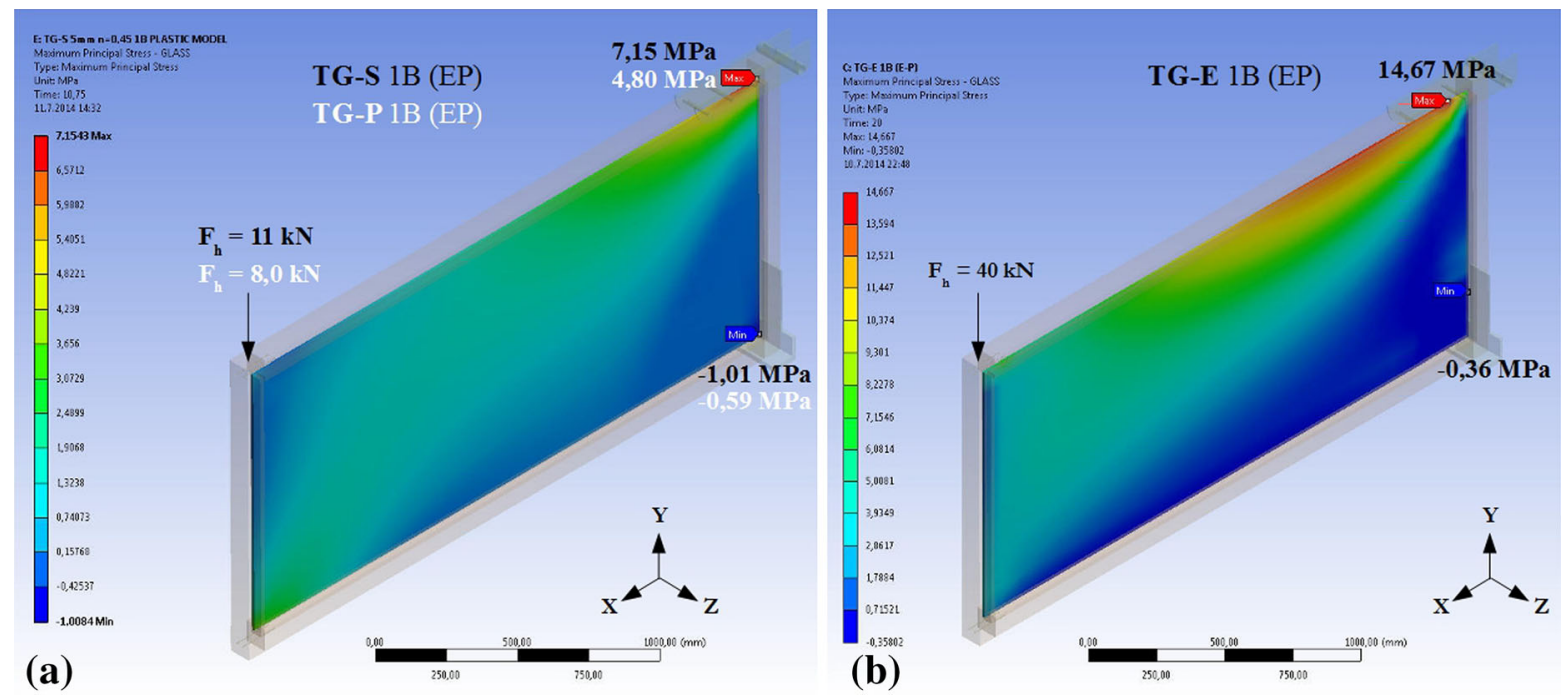

Fig. 14 Maximum and minimum values of principal stress in glass for models TG-S, TG-P and TG-E

to quasi-static cyclic load are added. In both cases (TGWE1 and TGWE2) wall elements exhibit a similar response up to $60 \mathrm{kN}$ of $F_{h}$, afterwards they fail at different values of horizontal load $\left(62 \mathrm{kN}<F_{h}<\right.$ $84 \mathrm{kN})$. Again a higher flexibility of numerical model S3a (EP) can be seen, which is now even more pronounced. However, more pronounced is also the difference between maximal horizontal displacements of $\mathrm{S} 3 \mathrm{a}(\mathrm{M})$ and S3a (EP), which is in favor of the latter.

Using a hyper-elastic material model of the adhesive joint seems to predict the initial stiffness better, but it overestimates the actual load-bearing capacity of TGWE. On the other side, the elasto-plastic material model of the adhesive joint slightly underestimates the initial stiffness, but more accurately describes the global response of the wall element.

\subsection{Stress-strain state in the adhesive joint and glass of TG and TGWE models}

In Fig. 14 principal stresses in glass with the local maxima and minima of numerical models TG-S, TG-P and TG-P-E can be observed. Since the stress state image of TG-S 1B (EP) and TG-P 1B (EP) is practically the same, double values are written in Fig. 14a.

In all three cases (TG-S, TG-P and TG-E), maximum value of the principal stress is located in the vicinity of supports. The fact that maximum stress at tension support is only two times higher at four times higher value of $F_{h}$, comparing TG-E 1B (EP) and TG-S 1B (EP), it is evident stresses are more evenly distributed over the glass pane. A similar phenomena is observed when analyzing TG-P 1B (EP). In this case, a five times lower vertical load yields only three times lower value of maximum stress at tension support, compared to TGE 1B (EP).

For a better insight into the performance of adhesive joints, the deformed shape of silicone and polyurethane together with strains in epoxy adhesive joint are shown on Fig. 15. The deformed shape of silicone and polyurethane adhesive joint clearly shows the rotation of the glass pane in a timber frame (Fig. 15a), causing tension strains in the upper-right and lower-left corner and compression strains in the opposite corners. Strains in epoxy adhesive joint (Fig. 15b) are directly connected with principal stresses in a glass plate (Fig. 14b), therefore the highest values in both cases are located at supports. Now it is evident that TG-E due to the stiff epoxy adhesive joint exhibits a fully composite action.

During mechanical tests a wall was deformed in form of a parallelogram, followed by shear failure of the adhesive joint in the corners. Larger global displacements of the wall caused the outer glass pane to detach from IGU. This failure mechanism began 

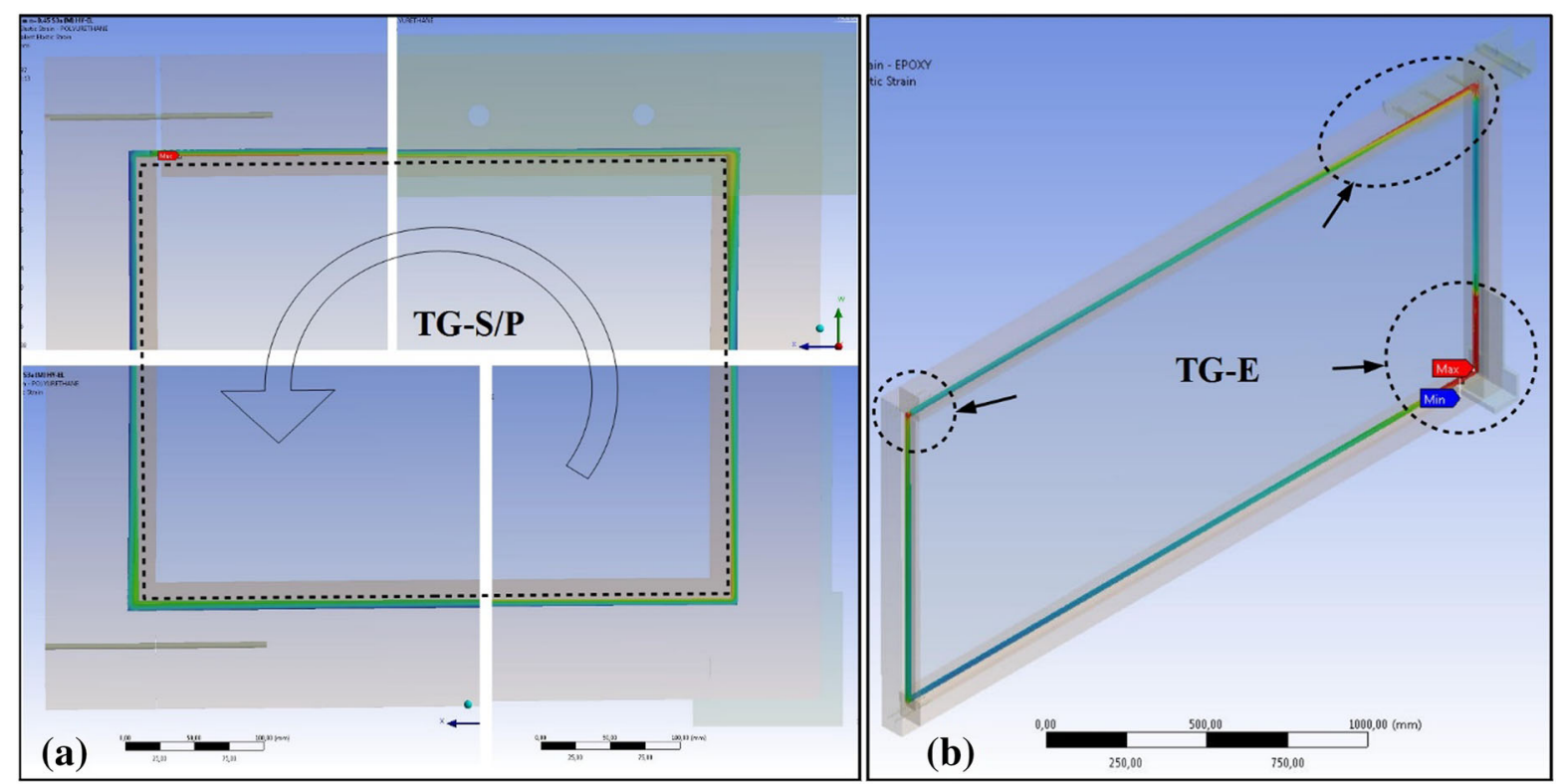

Fig. 15 Deformed model of silicone and PUR adhesive joint (a), and strains in epoxy adhesive joint (b)

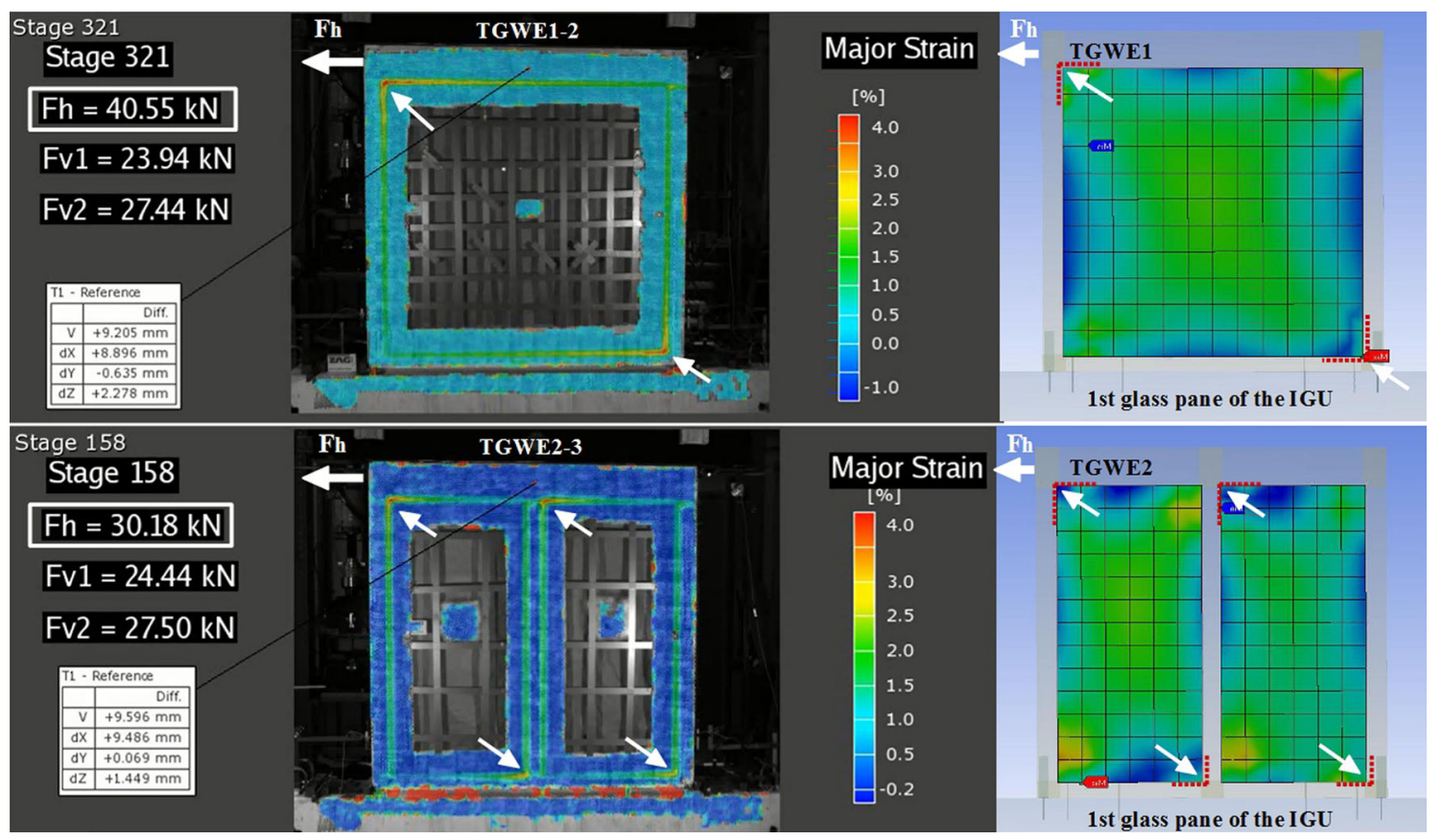

Fig. 16 Optical measurements of surface strains by GOM system (left) and FE simulation of the stress state in the glass (right) for both types of TGWE

to show at $F_{h} \approx 30 \mathrm{kN}$ in case of TGWE2-3 and at $F_{h} \approx 40 \mathrm{kN}$ in case of TGWE1-2. A parallel measurement of strains on the wall's surface by an optical system GOM confirms this phenomena. Figure 16 shows the comparison between the measured major strains on the wall's surface (left) and the von Mises stress state (right) in the first (i.e. outer) glass plate of IGU. 


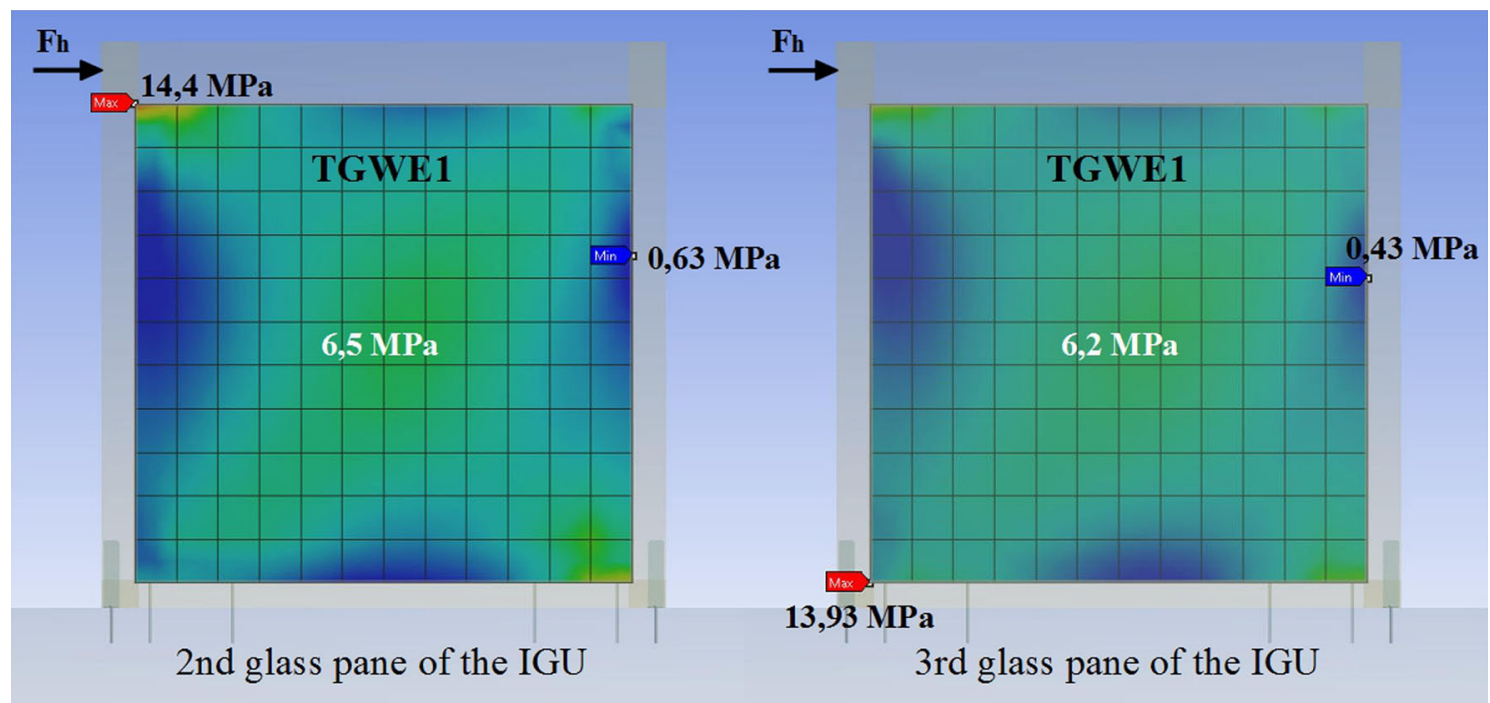

Fig. 17 State of stress in the second and third glass pane at $\mathrm{Fh}=70 \mathrm{kN}$ for TGWE1

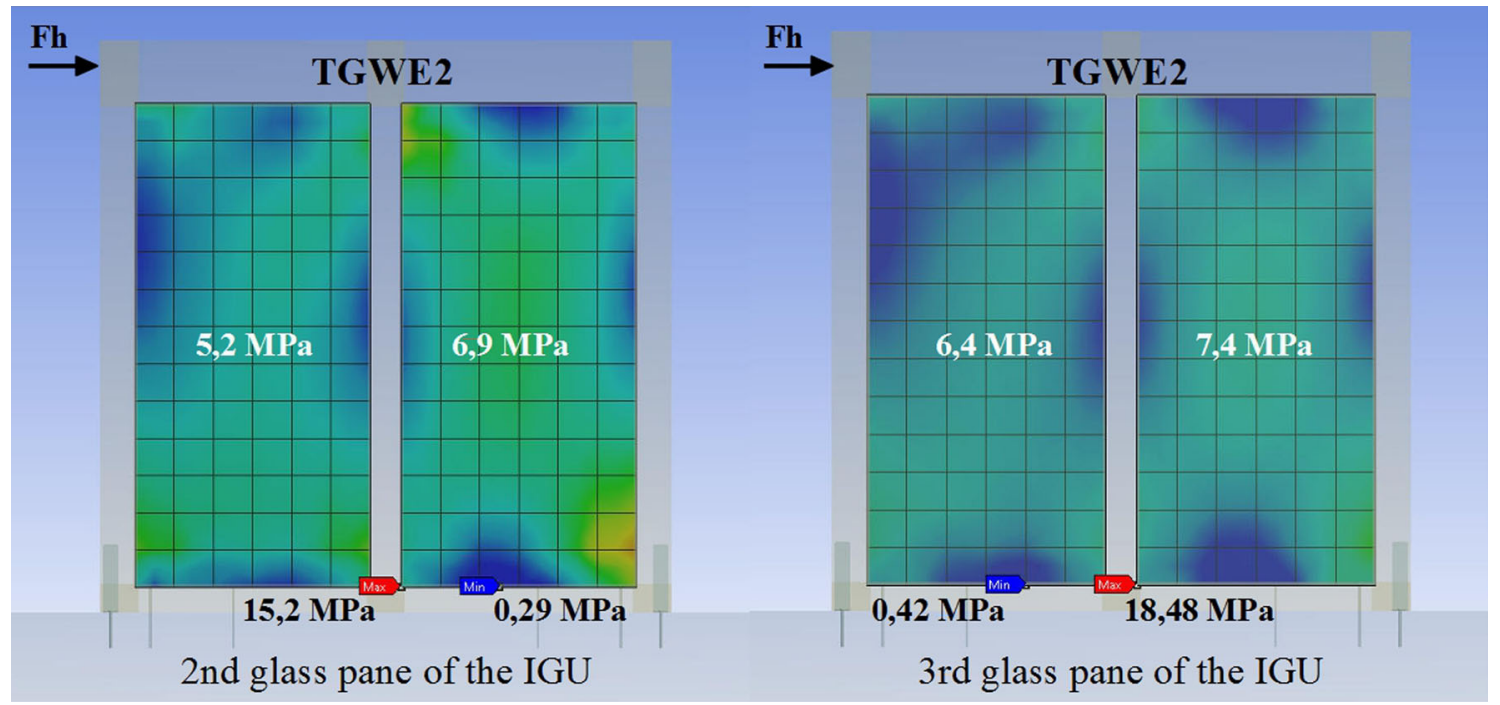

Fig. 18 State of stress in the second and third glass pane at $\mathrm{Fh}=70 \mathrm{kN}$ for TGWE2

In both cases (TGWE1-2 and TGWE2-3) the limit state of strains in the adhesive joint is evident. In upper left and lower right corners, measured major strains are reaching $4.0 \%$. In the same corners of numerical models (TGWE1 and TGWE2), stress in the glass pane at the surrounding area began to reduce, which indicates a gradual failure of the adhesive joint.

In continuation of mechanical tests, the second and third glass pane take over all (vertical and horizontal) load. Figures 17 and 18 present von Mises stress state in both glass plates for numerical models TGWE1 and TGWE2 at loading stage; $F_{h}=70 \mathrm{kN}$ and $F_{v}=60 \mathrm{kN}$.

In the case of TGWE1 (Fig. 17) the observed stress state is of the same magnitude, wherein the second glass pane is subjected to a slightly higher load.

In case of TGWE2 (Fig. 18), the stress in the third pane is slightly higher. The difference in stress magnitude between the second and third glass pane is quite noticeable (20\% for TGWE2), while in case of TGWE1 


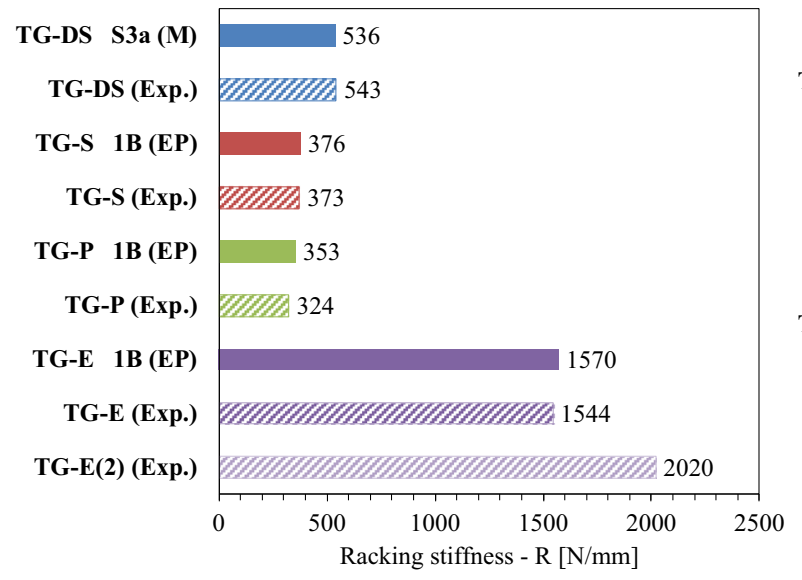

(a)

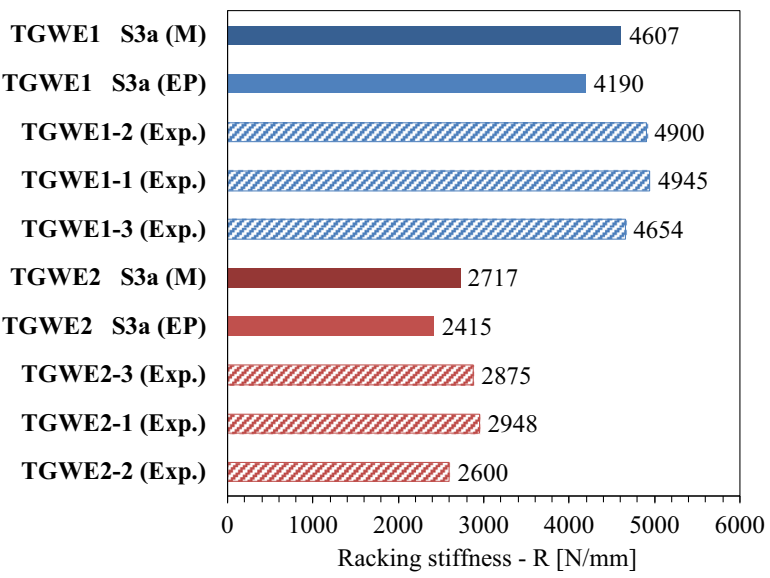

(b)

Fig. 19 Racking stiffness diagram of numerical models and experimentally investigated TG and TGWE type walls

the difference is only about $4.0 \%$. The difference in stress between the left and the right panes in TGWE2 is caused by the direction of the horizontal load.

\section{Conclusions}

The results of numerical analysis are in good agreement with the experimental analysis of TG walls. With accurate material models of adhesives, failure mechanisms are well simulated and calculated values of vertical displacements can be compared to measured ones.

For models with elastic adhesive joints (TG-DS, TG$\mathrm{S}$ and TG-P), we managed to capture the behaviour of experimentally tested wall elements, which was our main goal. For a better match, especially of the stressstrain state of the model, further investigations on bulk adhesives should be carried out to improve material models of flexible adhesives.

The response of TG-E model is the closest to actual situation. Vertical displacements and the stress-strain state of the numerical model are to a great extent comparable to measured values. The next step here is to use the elasto-plastic material model of timber to include irreversible deformations, which are absent at the moment.

Figure 19 shows a racking stiffness diagram, which includes selected numerical models and mean values of the experimentally investigated TG and TGWE walls. There is a good correlation in all four groups of numerical and physical models, with the negligible difference of stiffness $(<2.0 \%)$ in groups TG-DS, TG-S and TGE. However, the difference in group TG-P amounts to $8.9 \%$.

In case of TGWE, both material models of the polyurethane adhesive joint present a right choice. With the use of hyperelastic material model, a closer-toreality response was achieved, especially in the first part, as seen from diagrams in Figs. 13 and 19b. The stiffness of both numerical models S3a (M) in comparison with TGWE1-2 and TGWE2-3, differ by less than $6.0 \%$. In the second part of the simulation, a more realistic response is achieved with the use of an elastoplastic material model S3a (EP), which is evident as the numerical $F_{h}-v$ curve fits better in this final stage.

According to Figs. 17 and 18, we conclude that the stress state in the glass panes of IGU is the function of the IGU's position in the timber frame. By moving an IGU towards the mid-plane of the timber frame, a more even distribution of stress in the glass panes would be achieved. It would be sensible to carry out a parametric study of the IGU's position in a timber frame and to determine the size of this impact.

Acknowledgments The research support provided by the EU through the European Social Fund 'Investing in your future' is gratefully acknowledged.

\section{References}

ANSYS, Inc. Theory Manual. 001369. Twelfth Edition. SAS IP, Inc. Accessed June 2014 
Ber, B., Šusteršič, I., Premrov, M., Štrukelj, A., Dujič, B.: Testing of timber-glass composite walls. Proc. Instit. Civ. Eng.: Struct. Build. 168(7), 500-513 (2015). doi:10.1680/stbu. 13.00105

Ber, B., Premrov, M., Štrukelj, A., Kuhta, M.: Experimental investigations of timber-glass composite wall panels. Constr. \& Build. Mater. 66, 235-246 (2014)

da Silva, L., Campilho, R.: Advances in Numerical Modelling of Adhesive Joints. Springer, Heidelberg (2012)

de Borst, K., et al.: Mechanical characterization of wood: an integrative approach ranging from nanoscale to structure. Comput. Struct. (2012). doi:10.1016/j.compstruc.2012.11. 019

Deutsche Norm. DIN 53504.: Testing of rubber-determination of tensile strength at break, tensile stress at yield, elongation at break and stress in a tensile test, German Standard. Beuth Verlag GmbH (2010)

European Committee for Standardization. EN 594:1996: Timber structures - test methods-racking strength and stiffness of timber frame wall panels. Brussels (1996)

European Committee for Standardization. EN 1194:2000: Timber structures_-glued laminated timber strength classes and determination of characteristic values. Brussels (2000)

European Committee for Standardization. EN 12150-1:2000: Glass in building - thermally toughened soda lime silicate safety glass. Part 1: definition and description. Brussels (2000)

European Committee for Standardization. EN 338:2003: Structural timber-strength classes. Brussels (2003)

European Committee for Standardization. EN 572-1:2004: Glass in building — basic soda lime silicate glass products-Part 1: definitions and general physical and mechanical properties. Brussels (2004)
European Committee for Standardization. EN 594:2011: Timber structures - test methods - racking strength and stiffness of timber frame wall panels. Brussels (2011)

European Committee for Standardization. EN ISO 527-2:2012. Plastics-determination of tensile properties-Part 2: test conditions for moulding and extrusion plastics. Brussels (2012)

Feldmann, M., Kasper, R. et al.: JRC Scientific and Policy Report - Guidance for European Structural Design of Glass Components. Publications Office of the European Union, Luxembourg (2014). doi:10.2788/5523

Green, D.W., Winandy, J.E., Kretschmann, D.E.: Mechanical properties of wood. In: Wood Handbook: wood as an Engineering Material, Chapt. 4.1-4.45. USDA Forest Service GTR-113 (1999)

Huveners, E.M.P.: Circumferentially adhesive bonded glass panes for bracing steel frames in facades. Ph.D Thesis. University of Technology Eindhoven, Eindhoven (2009)

International Standard. ISO 16670:2003(E): Timber structuresjoints made with mechanical fasteners-quasi-static reversed-cyclic test method. Zurich (2003)

Kolb, J.: Systems in Timber Engineering. Birkhäuser Verlag AG, Basel (2008)

Niedermaier P.: Holz-Glas-Verbundkonstruktionen. Ein Beitrag zur Aussteifung von filigranen Holztragwerken. Ph.D Thesis. University of Technology Munich, Munich (2005)

Overend, M., Jin, Q., Watson, J.: The selection and performance of adhesives for a steel-glass connection. Int. J. Adhes. Adhes. 31, 587-597 (2011)

Žegarac Leskovar V., Premrov M.: Energy-Efficient TimberGlass Houses, (Green Energy and Technology). Springer, London (2013). doi:10.1007/978-1-4471-5511-9 